\title{
Separable Roles for Exonuclease I in Meiotic DNA Double-Strand Break Repair
}

Rebecca E. Keelaghera, Victoria E. Cottona, Alastair S.H. Goldmanb and Rhona H. Bortsa*

a Department of Genetics, University of Leicester, University Road, Leicester, LE1 7RH, United Kingdom.

b Department of Molecular Biology \& Biotechnology, Krebs Institute, The University of Sheffield, Sheffield, S10 2TN, United Kingdom.

* Corresponding author

Tel: +44 1162522294

Fax: +44 1162523378

Email: rhb7@le.ac.uk 


\begin{abstract}
Exo1 is a member of the Rad2 protein family and possesses both $5^{\prime}-3^{\prime}$ exonuclease and $5^{\prime}$ flap endonuclease activities. In addition to performing a variety of functions during mitotic growth, Exo1 is also important for the production of crossovers during meiosis. However, its precise molecular role has remained ambiguous and several models have been proposed to account for the crossover deficit observed in its absence. Here, we present physical evidence that the nuclease activity of Exo1 is essential for normal 5'-3' resection at the Spo11-dependent HIS4 hotspot in otherwise wild-type cells. This same activity was also required for normal levels of gene conversion at the locus. However, gene conversions were frequently observed at a distance beyond that at which resection was readily detectable arguing that it is not the extent of the initial DNA end resection that limits heteroduplex formation. In addition to these nuclease-dependent functions, we found that an exo1-D173A mutant defective in nuclease activity is able to maintain crossing-over at wild-type levels in a number of genetic intervals, suggesting that Exo1 also plays a nuclease-independent role in crossover promotion.
\end{abstract}

Keywords: EXO1, meiosis, recombination, resection, double-strand break. 


\section{Introduction}

During meiosis, recombination is initiated by the formation of DNA double-strand breaks (DSBs) catalysed by the Spo11 protein [1]. Once DSB formation has been achieved, Spo11 must be removed from the DNA ends in order for repair to commence. This removal takes place via endonucleolytic cleavage of the DNA to release Spo11-oligonucleotide complexes [2]. Further DNA end resection then follows resulting in longer $3^{\prime}$ overhanging strands [3, 4]. These strands are bound by Rad51 and Dmc1 to form the recombinogenic nucleoprotein filaments required to catalyse strand-invasion [5].

DSBs may be repaired to yield either crossovers or non-crossovers and it is thought that the decision as to which repair pathway is utilised is made at or around the point of strand invasion. The stabilisation of a nascent D-loop to form a single-end invasion (SEI) is the first molecularly measurable event that defines the major crossover pathway [6]. Subsequently, double Holliday junctions (dHJs) are produced $[7,8]$, resolution of which by an as yet unidentified factor(s) yields a crossover. A number of proteins are required for this process [9] including the Msh4/Msh5 heterodimer [10,11], which is believed to encircle and stabilise D-loop and Holliday junction structures [12] and the Mlh1/Mlh3 heterodimer. Mlh1/Mlh3 are thought to function after Msh4/Msh5 and may be required (either directly or indirectly) for Holliday junction resolution [13-17]. A minority of crossovers also form independently of the Msh4/Msh5 pathway, many of which are dependent upon the structure-specific endonuclease complex Mus81/Mms4 [18-20]. While physically detectable intermediates specific to the non-crossover pathway have not been identified, it is thought likely to proceed via synthesis-dependent strand-annealing $[21,22]$. The initiating events in this pathway are similar to those in the crossover pathway; however, a detectable SEI intermediate is not produced. Instead, following DNA synthesis, the invading strand is displaced and anneals to the complementary sequence uncovered by resection on the opposite side of the DSB. DNA synthesis then acts to fill in the remaining gaps, followed by ligation of the DNA ends.

Exo1 (a member of the Rad2/XPG family of nucleases) possesses both 5'-3' exonuclease and 5' flap endonuclease activities [23] and has been shown to be 
involved in a wide variety of cellular processes during mitotic growth. In yeasts [2426], Drosophila [27] and mice [28], expression of Exo1 is strongly up-regulated in cells undergoing meiosis suggesting an important conserved role for Exo1 during the recombination process. To date, the most comprehensive analyses concerning the meiotic role of Exo1 have been carried out in the yeast Saccharomyces cerevisiae. In this organism, crossing-over was shown to be reduced 1.5-2 fold in exol $\Delta$ strains compared to wild type $[25,29,30]$. Consequently, increased levels of meiosis I nondisjunction occurred resulting in the formation of aneuploid spores. Compared to any single mutant, no further reduction in crossing-over was observed in exol $\Delta \mathrm{msh} 4 \Delta$ or exol $\Delta$ msh5 $\Delta$ double mutants suggesting that Exo1 acts to promote inter-homologue crossing-over via the Msh4/Msh5 pathway [29, 30].

These studies also indicated that deletion of EXO1 confers allele and/or locus specific effects on gene conversion [29, 30]. While Tsubouchi et al. [25] were unable to detect any reduction in gene conversion at ARG4 or the artificial HIS4:LEU2 hotspot using recombination assays between heteroalleles, Khazanehdari \& Borts [30] reported a significant two-fold reduction in gene conversion at all four alleles of HIS4 studied. They also noted an approximately two-fold reduction in conversion at two alleles of MET13 and at one of the three LEU2 alleles tested. Conversely, Kirkpatrick et al. [29] reported no effect on the gene conversion of markers at HIS4 but did observe a significant reduction at $A R G 4$. As gene conversion requires the incorporation of allelic markers into heteroduplex DNA (hDNA) [31], Exo1 may therefore be required for the formation or extension of hDNA tracts. In view of these results and the biochemical function of Exo1 as a nuclease, it has been suggested that Exo1 functions in the resection of meiotic DSBs prior to strand invasion [25, 30]. This has been demonstrated recently at mitotic DSBs [32, 33].

To date, experiments designed to demonstrate a direct role for Exo1 in meiotic resection have relied upon deletion of $D M C 1$ to aid the visualisation of resection intermediates on Southern blots [25, 34]. In the absence of $D M C 1$, breaks are unable to undergo strand invasion and hyper-resected DSBs accumulate [35]. While these studies demonstrated that Exo1 is partially responsible for the hyper-resection observed, it remains unclear as to what extent this reflects normal patterns of 
resection. Additionally, there is uncertainty as to how Exo1 acts to promote crossingover. It has been proposed that decreased resection following DSB formation may reduce the stability of initial strand invasion attempts, resulting in fewer SEIs being formed [30]. However, observations from mice indicate that when Exo1 is absent, meiotic defects only become apparent at a later stage (after the crossover function of Msh4/Msh5)[36, 37]. This argues that a reduction in resection may not account for the crossover deficit observed and that Exo1 may have an alternative critical function during meiosis.

In this work, we aimed to determine whether or not Exo1 is required for normal resection following Spo11-catalysed DSB formation in otherwise wild-type cells. We further sought to test the hypothesis that resection tract length correlates with hDNA formation and ultimately determines the propensity with which a DSB is repaired to yield a crossover. To do this we employed both physical and genetic methods of analysis, focussing upon the natural HIS4 hotspot, where Exo1 has previously been implicated in DSB processing [30].

\section{Materials and Methods}

\subsection{Yeast strains and media}

All strains are derivatives of the Saccharomyces cerevisiae SK1 isolate [38]. The alleles used have been described previously [19, 39-43] and were introduced by transformation or crossing to existing strains. The EXOI ORF was replaced with the kanMX4 cassette conferring resistance to geneticin as described by Wach et al. [44] using the plasmid template pFA6-kanMX4. The exol-D173A mutation was introduced via a PCR-based allele replacement method [45] using plasmid template pEAM71 [46]. All alleles were confirmed by PCR, restriction digest and linkage analysis where appropriate. The exol-D173A mutation was confirmed by DNA sequencing. Full strain genotypes are listed in Tables 1 and 2. The media used have been described previously [47].

\subsection{Liquid sporulation}

For tetrad analysis, haploid strains were mixed and allowed to mate for 4 hours on YPD at $30^{\circ} \mathrm{C}$ before being replicated to minimal medium (supplemented with $240 \mu \mathrm{l}$ 
of $0.5 \%(\mathrm{w} / \mathrm{v})$ adenine hemisulphate per plate) to select for diploids and grown overnight at $30^{\circ} \mathrm{C}$. For the physical analysis and random spore experiments, pure diploid colonies were used. Sporulation conditions were the same for all experiments. Cultures were grown to saturation in YPD, diluted 1:400 into SPS (supplemented with $40 \mathrm{mg} / \mathrm{ml}$ adenine hemisulphate) and grown to a cell density of $5.5 \times 10^{7}$ cells $/ \mathrm{ml}$. Cells were harvested by centrifugation, washed once in $2 \%(\mathrm{w} / \mathrm{v})$ potassium acetate $(\mathrm{pH} 7)$ and finally resuspended in $2 \%(\mathrm{w} / \mathrm{v})$ potassium acetate $(\mathrm{pH} 7)$ in $1.5 \mathrm{x}$ the volume of SPS used. These cultures were transferred to a $2.8 \mathrm{~L}$ baffled flask and incubated with vigorous shaking at $23^{\circ} \mathrm{C} .23^{\circ} \mathrm{C}$ was chosen as the sporulation temperature as gene conversion and DSBs at the HIS4 hotspot have been shown to be temperature-dependent, occurring at a higher frequency at lower temperatures $[47$, 48]. For DNA analysis, aliquots were removed ( $25 \mathrm{ml}$ up to 5 hours and $15 \mathrm{ml}$ thereafter) and $10 \%(\mathrm{w} / \mathrm{v})$ sodium azide added to a final concentration of $0.1 \%(\mathrm{w} / \mathrm{v})$ before harvesting by centrifugation and storing of the cell pellets at $-80^{\circ} \mathrm{C}$. For tetrad and random spore analysis, cell samples were taken after 24 hours sporulation and processed immediately.

\subsection{Genetic analysis}

Tetrad dissection and analysis was carried out as described previously [49]. Crossingover and gene conversion (6:2, 2:6 segregation) was assessed in tetrads with four viable spores. Tetrads exhibiting three or more non-Mendelian segregation events (any segregation pattern other than 4:4) were scored as false tetrads and excluded from further analysis. Map distances in centiMorgans (cM) were calculated as described by Perkins et al. [50]. Random spores were prepared according to the protocol outlined by Jessop et al. [51] and appropriate dilutions were plated out onto two types of media: synthetic complete and synthetic complete lacking histidine, both of which were supplemented with $60 \mu \mathrm{g} / \mathrm{ml}$ canavanine and $10 \mu \mathrm{g} / \mathrm{ml}$ cyclohexamide. The double drug selection ensured that only haploid meiotic products were analysed. Spores were incubated at $30^{\circ} \mathrm{C}$ for 3 days before individual colonies were patched onto YPD. Following growth overnight at $30^{\circ} \mathrm{C}$, the patches were replicated to YPD supplemented with either $300 \mu \mathrm{g} / \mathrm{ml}$ hygromycin B or $100 \mu \mathrm{g} / \mathrm{ml}$ nourseothricin. After a further overnight incubation at $30^{\circ} \mathrm{C}$, patches were scored for their ability to grow on these plates. Statistical comparisons were made using either the G-test of 
homogeneity or the $t$-test as appropriate and the Dunn-Sidak correction for multiple testing was applied [52]. This guards against type 1 errors but increases the probability of type 2 errors.

\subsection{Loss of restriction site analysis by $q P C R$}

In order to measure resection intermediates without having to rely upon the use of the $d m c 1 \Delta$ mutation or an artificial hotspot, we modified an assay developed by Hodgson et al. [53] that measures single-stranded DNA (ssDNA). This assay uses restriction enzyme digestion to cleave all double-stranded DNA (dsDNA) at a specific target site, followed by quantitative PCR (qPCR) using a pair of oligonucleotide primers designed to anneal each side of the enzyme cut site. Any DNA present at the target site in single-stranded form (such as that produced by $5^{\prime}-3^{\prime}$ resection) becomes refractory to enzyme cleavage and is therefore able to be amplified in the subsequent PCR step. A second qPCR reaction is directed to the rDNA array. No target sites for any of the restriction enzymes used are present within the rDNA region chosen, enabling it to serve as an internal measure of the amount of DNA per reaction. The oligonucleotide sequences used for these experiments are given in Table 3.

DNA was extracted from cells using a modified version of the CTAB method [54] in which hexamine cobalt chloride was omitted from all solutions and the DNA resuspended in 100-150 $\mu \mathrm{l}$ of $1 \mathrm{x}$ TE. For each time point, approximately $750 \mathrm{ng}$ of genomic DNA was digested with 25 units of enzyme for 30 mins at $37^{\circ} \mathrm{C}$ in a total volume of $50 \mu \mathrm{l}$. Following digestion, $20 \mu \mathrm{l}$ of the digest was diluted into $80 \mu \mathrm{l}$ of ice-cold water, $2 \mu \mathrm{l}$ of which was added to each qPCR reaction to give approximately 6ng of template DNA per reaction. The qPCR reactions were carried out in a total volume of $10 \mu \mathrm{l}$ using 1x SensiMix ${ }^{\text {TM }}$ SYBR (Bioline) and $400 \mathrm{nM}$ forward and reverse oligonucleotides. At each time point, qPCR was directed to both the target site of interest and the rDNA region. Thermocycling was carried out using a LightCycler ${ }^{\circledR} 480$ Real-Time PCR System (Roche). PCR reactions were initiated by heat activation of the $\mathrm{Taq}$ polymerase at $95^{\circ} \mathrm{C}$ for $10 \mathrm{mins}$, followed by 40 cycles of $95^{\circ} \mathrm{C}$ for $15 \mathrm{~s}$ and $60^{\circ} \mathrm{C}$ for $1 \mathrm{~min}$. All reactions were performed in triplicate and "notemplate" controls for each oligonucleotide pair used were included in every run. Amplicons were between 100 and 150 base pairs in length and primer specificity was 
validated by melt-curve analysis. Standard curves were included on every plate and were constructed from a five-point 1 in 10 serial dilution of DNA taken from the 0 hour time point of the time course being analysed (starting from approximately $25 \mathrm{ng}$ template DNA per reaction). Crossing-point ( $\mathrm{Cp}$ ) values were calculated using the automated $\mathrm{Cp}$-calling algorithm provided by the LightCycler® Analysis Software (based on the second derivative maximum method). In general, the mean $\mathrm{Cp}$ value of the three replicates was used for subsequent analysis. However, if a single reaction differed from its duplicates by more than one $\mathrm{Cp}$ value, it was discarded and the mean $\mathrm{Cp}$ value of the remaining two reactions used instead.

Mean $\mathrm{Cp}$ values for each triplicate sample were imported into Microsoft Excel and standard curves constructed for both the target site primer pair and rDNA primer pair by plotting the mean $\mathrm{Cp}$ values obtained against the $\log ^{10}$ of the dilution factor used. A line of best fit was drawn and the slope $(m)$ and y intercept $(b)$ of the line calculated. For each experimental sample, a value for the amount of template DNA present at the start of the PCR $(x)$ at both the target and rDNA loci were obtained by reference to the appropriate standard curve using the formula:

$$
x=10^{\frac{\text { MeanCp-b }}{m}}
$$

The relative proportions of ssDNA and dsDNA in the sample were then calculated using the equations:

$$
\begin{aligned}
& \% S S D N A_{\text {MEASURED }}=\frac{x_{\text {TARGET }}}{x_{r D N A}} \times 100 \\
& \% d S D N A_{\text {MEASURED }}=100-\left[\frac{x_{\text {TARGET }}}{x_{r D N A}} \times 100\right]
\end{aligned}
$$

In order to compare between different target sites and time courses, it was necessary to normalise the data from each experiment to take account of the efficiency with which digestion of dsDNA had occurred. This was done by reference to the amount of ssDNA measured in the 0 hour time point of that time course (where 0 hour is assumed to represent $100 \%$ dsDNA) using the equation: 


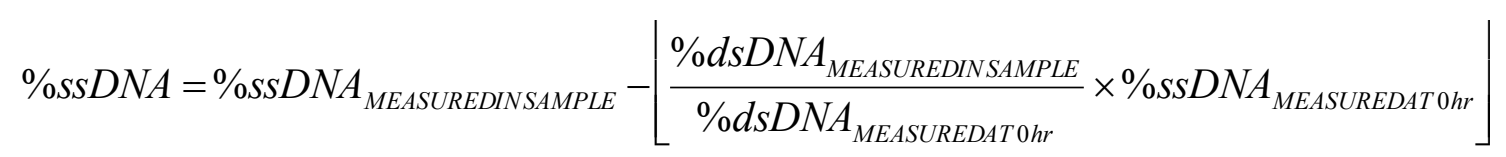

The ssDNA values calculated provided a conservative estimate of the overall proportion of chromatids resected as the resected strand was unable to serve as a template for PCR in the first amplification cycle.

\subsection{Southern blot analysis}

Approximately $3 \mu \mathrm{g}$ of genomic DNA was digested with 25 units of $B g l \mathrm{II}$ at $37^{\circ} \mathrm{C}$ for 3.5 hours in a total volume of $80 \mu \mathrm{l}$. The DNA was separated on a $0.7 \%$ agarose gel before transfer to a nylon membrane in 20x SSC and probing with an $\alpha-{ }^{32} \mathrm{P}$ radiolabelled HIS4 fragment ( +523 to $+1,547$ base-pairs, relative to the HIS4 open reading frame). Hybridisation and washing was carried out as described in Allers and Lichten [55]. Bands were quantified using a Typhoon Phosphorimager (GE Healthcare) and CellQuant software. The percentage of DSBs present in each time point was calculated using the formula:

$\% D S B S=\left[\frac{D S B \text { signal }}{D S B+\text { parental signal }}\right] \times 100$

\subsection{Cumulative curves}

In order to convert the non-cumulative DSB frequencies into cumulative curves, the background DSB signal measured at 0 hours was subtracted from each time point. The DSB lifespan in each time course was then calculated as described by Padmore et $a l$. [56] by dividing the area under the non-cumulative curve by the amount of DSB measured in rad50S strains. Subsequently, the areas between each adjacent pair of time points under the noncumulative curve were divided by the lifespan of the DSB and the resulting values describing the proportion of total DSBs present at each time point summed to produce a cumulative curve. Cumulative curves for ssDNA were calculated in the same way. For all time courses, the lifespan of each resection intermediate was assumed to be equivalent to the lifespan of the DSB in the same time course.

\section{Results}




\subsection{Resection at the natural HIS4 hotspot requires the nuclease activity of Exo1}

DSBs at the natural HIS4 hotspot are spread over an approximately $200 \mathrm{bp}$ region which centres approximately 300 bp upstream of the HIS4 start codon [42, 57] (Supplemental Figure 1A). In a rad50S strain where unresected DSBs accumulate [43], approximately $13 \%$ of all molecules receive a DSB at HIS4 when assessed by Southern blotting and this is unaffected by the status of EXOI (Methods 2.5 and Supplemental Figure 1A). There are no other DSBs within $1.3 \mathrm{~kb}$ upstream or $5.9 \mathrm{~kb}$ downstream of the HIS4 ORF (Supplemental Figure 1B). We first characterised resection in a wild-type strain by measuring the amount of ssDNA produced the NheI, ClaI, Aat II and BglII restriction sites (situated approximately $0.5 \mathrm{~kb}, 0.8 \mathrm{~kb}$, $1.25 \mathrm{~kb}$ and $2 \mathrm{~kb}$ from the HIS4 hotspot respectively) at various time points throughout meiosis (Figure 1A). This was done using a qPCR-based assay that specifically amplifies ssDNA (Methods 2.4). Attempts to measure ssDNA closer to the break site were unsuccessful, perhaps due to DSBs occurring within the amplicon or degradation of the $3^{\prime}$ end. DSB formation at the HIS4 locus was also measured from the same time courses using quantitative Southern blot analysis and the results from these experiments are presented in Figure 1B. In contrast to previous reports (based on degree of DSB "smearing") in which DSBs were purported to exhibit a constant degree of resection at all time points $[35,58]$, we observed a slight delay in resection reaching the sites used in this study. Thus, a greater proportion of the DSBs persisting at later time points were subject to detectable resection compared to those in earlier time points. This suggests that the processivity of resection in these experiments is slower than has been observed previously. There are a number of potential explanations for this including differences in the assays used to estimate resection and the temperature of sporulation. Additionally, if the DNA/chromatin context affects resection [53], it may be the case that the natural HIS4 locus is less amenable to processive resection than the loci used in previous studies.

In order to estimate the overall proportion of DSBs resected as far as each target site over the entire time course, cumulative curves for both DSBs and ssDNA were constructed (Figures 1C, Methods 2.6). From this we demonstrate that there is a very sharp resection gradient in wild-type cells, with the vast majority of resection terminating before reaching the AatII site (955 bp from HIS4, approximately $1.25 \mathrm{~kb}$ 
from the DSB). As can be seen in Figure 1D, when ssDNA was measured in exo1 $\Delta$ cells there was considerably less resection than in the wild type (2.3x less at $500 \mathrm{bp}$ from the DSB and 5x less at the site approximately 800 bp away). This difference is entirely due to loss of the nuclease activity of EXO1 as DSBs in a strain containing an EXO1 allele that remains structurally intact but is defective in nucleolytic activity, exo1-D173A [23, 46], also underwent very little resection (Figure 1B).

\subsection{Resection tract length does not strictly correlate with frequency of gene conversion}

It has previously been proposed that EXOI is responsible for the $5^{\prime}-3^{\prime}$ resection of meiotic DSBs and that a gradient of resection could contribute to the formation of gene conversion gradients $[4,30,31]$. Therefore, we assessed the effect that deleting EXO1 had on the HIS4 gene conversion gradient by tetrad dissection of strains containing alleles both proximal and distal to the DSB. Deletion of EXO1 significantly reduced the levels of gene conversion measured at both alleles (Figure 2; $\mathrm{p}<0.0256$, G-test). While this was similar to the effect that EXO1 deletion had upon the resection gradient, there did not appear to be a direct correlation between resection and conversion. This was most clearly demonstrated in the wild-type strain in which over one third of the gene conversion tracts that were measured $96 \mathrm{bp}$ from the start codon (approximately $400 \mathrm{bp}$ from the DSB) also extended as far as 1,688 bp away (approximately $2 \mathrm{~kb}$ from the DSB; Figure 2). However, despite significant quantities of resection being observed $500 \mathrm{bp}$ from the DSB, virtually no ssDNA was detected at the site of the DSB distal allele even though considerable amounts of hDNA must have formed there (Figures 1 and 2). This argues that more hDNA is produced during meiosis than can be accounted for by detectable resection of the DSB. Accordingly, the slopes of the resection gradients in the region assessed were approximately 3-fold greater than the slopes of the conversion gradients in both wild-type and exol $\Delta$ strains (Figures 1D and 2).

In order to rule out the possibility that the requirement for Exo1 in gene conversion at HIS4 was a locus-dependent effect, we also tested the effect of exol $\Delta$ at 7 other alleles. There was a significant reduction in gene conversion at two of these loci (Table 4) when compared to wild type. At the five other loci, gene conversion was 
also reduced but the frequencies measured were individually too low to obtain statistically significant results. However, the probability of observing the rates of gene conversion at all five loci changing in the same direction in exol $\Delta$ cells (ie: less than wild-type) if exol $\Delta$ had no effect is $\mathrm{p}=0.031$ (binomial exact probability). If we enlarge the group to include the four other loci, then the probability of all 9 exhibiting lower conversion levels in exol $\Delta$ is $\mathrm{p}<0.002$. Thus in the strains used here, deletion of EXO1 significantly reduces gene conversion. Furthermore, the influence of Exo1 on heteroduplex tract length appears to be dependent upon the nucleolytic activity of the enzyme as gene conversion at the his4-xho and leu2-r alleles was also significantly reduced when measured in exol-D173A. However, there was no significant change in the frequency of gene conversion at the 7 remaining alleles in this strain, perhaps due to the numbers of tetrads assessed.

\subsection{Crossovers are maintained when the nuclease activity of Exo1 is absent}

We next sought to determine if the reduced hDNA tracts and reduced resection observed in the absence of the nuclease activity of Exo1 correlated with reduced crossing-over. To do this, we analysed recombination in a range of genetic intervals on three chromosomes (Figure 3A) in wild type, exo1 $\Delta$ and exol-D173A tetrads. Consistent with previous studies, deletion of EXO1 resulted in a statistically significant 1.5-2 fold reduction in crossing-over in all intervals examined (Figure 3C, Supplemental Table 1). This reduction in crossing-over was accompanied by a significant decrease in spore viability (Figure 3B, Supplemental Table 2) from 95.8\% to $60.4 \%$ and a significant alteration in the distribution of viable spore tetrad classes. The exol $\Delta$ spore viability measured in this work was significantly lower than that reported previously in the SK1 background by Tsoubouchi et al. [25]. This can be accounted for by the difference in the temperature of sporulation used in each study as increasing temperature in exol $\Delta$ strains appears to improve homologue disjunction at meiosis I (Supplemental Table 2). An effect of temperature upon spore viability has been reported previously in $m s h 4 \Delta$ [59] and pch2 $\Delta$ [60] mutants.

Surprisingly, crossing-over in exol-D173A tetrads was significantly higher than in exo1 $\triangle$ cells in all but the HIS4-LEU2 and CEN8-ARG4 intervals. The only interval with significantly reduced crossing-over in exo1-D173A cells compared to wild type 
was LEU2-MAT (Figure 3B, Supplemental Table 1). As there is little crossover deficit in exo1-D173A cells, the crossover defect observed in the exol $\Delta$ strain is unlikely to be due to a defect in exonuclease activity. Instead, Exo1 may also play a structural role in promoting crossing-over. Consistent with the near wild-type levels of crossing-over in exo1-D173A meiosis, spore viability was significantly improved compared to the exol $\Delta$ strain and there were fewer meiosis I non-disjunctions (Figures 3B, 3D; Supplemental Table 3). However, the pattern of spore viability was different from wild type with more tetrads containing a single dead spore (Figure 3B, Supplemental Table 2). A potential explanation for this effect is discussed in 4.4 and illustrated in Figure 5.

\subsection{The relationship between hDNA tract length and crossover formation}

In order to further investigate the apparent discordance between hDNA tract length and crossing-over, we sought to measure the association of crossing-over with gene conversion at the HIS4 hotspot. Ideally, one would use tetrad analysis to identify gene conversions at alleles placed varying distances from the DSB and determine the frequency with which they are associated with crossing-over. However, due to the relatively low frequency of gene conversion at the distal allele used (his4-bgl) such an approach was not feasible. In order to obtain sufficient gene conversions to accurately assess crossover association, we instead designed a random spore assay based on his 4 heteroalleles and selected $\mathrm{His}^{+}$prototrophic recombinants. We constructed two heteroallelic diploids: his4-xho/his4-cla and his4-cla/his4-bgl (Figure 4). In systems such as this one, the majority of $\mathrm{His}^{+}$prototrophs derive from recombination events in which the hDNA tract or the mismatch repair tract terminates between the two alleles (Supplemental Figure 2). Thus, $\mathrm{His}^{+}$prototrophs arising from the his4-xho/his4-cla heteroalleles require hDNA to extend past his4-xho but terminate prior to reaching the his4-cla allele and are therefore 'short'. In contrast, prototrophs from a his4-cla/his4-bgl diploid come from 'long' events terminating after his4-cla but before his4-bgl.

We selected $600 \mathrm{His}^{+}$prototrophs from wild-type, exo1 $\Delta$ and exol-D173A strains containing these two pairs of heteroalleles. The association of each event with crossing-over was determined by the arrangement of the flanking markers. Like all 
such assays (for example, that of Martini et al. [39]), one of the two possible recombinants and one of the two potential parental configurations are favoured due to the placement of the heteroalleles and the nature of the selection (Supplemental Figure 2). For example, since the parental strand undergoing DSB formation is the recipient of information, $\mathrm{His}^{+}$events in the his4-cla/his4-bgl cross preferentially arise when the his4-cla strand is broken. This leads to the selective recovery of $\mathrm{His}^{+} \mathrm{Nat}^{\mathrm{R}}$ $\mathrm{Hyg}^{\mathrm{R}}$ non-crossover recombinants and $\mathrm{His}^{+} \mathrm{Nat}^{\mathrm{R}}$ crossover recombinants. Similarly in the his4-xho/his4-cla cross, prototrophs arise predominantly when the his4-xho strand is broken resulting in $\mathrm{His}^{+}$non-crossovers that are drug sensitive and crossovers that are $\mathrm{Nat}^{\mathrm{S}} \mathrm{Hyg}^{\mathrm{R}}$ (Table 5, Supplemental Figure 2).

In addition to the gene conversion events, the configuration of flanking markers was also analysed in 600 spores without first selecting for histidine prototrophy in order to assess the overall rate of crossing-over in the interval. No statistically significant differences (G-test, $p>0.0258$ ) between strains were detected using this approach although the difference between the wild-type and the exol $\Delta$ strain was $\mathrm{p}=0.03$. However, the pattern of crossing-over measured (Table 6) mirrored that observed by tetrad analysis in the HIS4-LEU2 interval and the adjacent LEU2-MAT interval where exo1-D173A cells exhibited a crossover frequency intermediate between the wild-type and exol $\Delta$ strains. This suggests that for recombination initiating at HIS4, both the nuclease-dependent and independent functions of Exo1 are required for crossing-over to proceed as normal. We predicted that if exol-D173A cells were able to maintain crossing-over despite reduced hDNA formation, an increase in the association of gene conversions with crossing-over would be evident. Consistent with this, crossing-over in exol-D173A spores was significantly increased compared to wild-type when both 'short' and 'long' hDNA tracts were selected for (Table 5). Furthermore, a significant reduction in crossover association was observed in exol $\Delta$ cells compared to exol$D 173 A$ when 'short' hDNAs had been produced. This suggests that the non-catalytic function of Exo1 is important for ensuring that shorter hDNA tracts undergo crossingover. When longer hDNA tracts were selected for, no such reduction in association was observed, arguing that intermediates containing longer hDNA tracts do not require Exo1 to be resolved into crossovers. 


\section{Discussion}

\subsection{DSB end resection is reduced when EXO1 is absent}

In exo1 1 , the extent to which DSBs are resected is reduced. Furthermore, the data are consistent with all DSBs being resected less, rather than a subset of DSBs being selectively processed by Exo1. A more severe defect was observed when ssDNA was measured approximately $800 \mathrm{bp}$ from the DSB compared to $500 \mathrm{bp}$, suggesting that the residual resection occurring in the absence of Exo1 is less processive. This is consistent with the data of Hodgson et al. [53] based on their analysis of resection at a break induced by the VMAl-derived endonuclease (VDE). The identity of the protein(s) responsible for this remaining resection is unclear. A recent study demonstrated a role for Sgs1 and Dna2 in producing the hyper-resected intermediates that form during meiosis in $d m c 1 \Delta$ mutants [34]. This is reminiscent of the dual resection pathways mediated by Exo1 and the 5' single-stranded exonuclease Dna2 (in conjunction with the helicase Sgs1 to first unwind the DNA) at DSBs occurring during mitotic growth $[32,33]$. However, if these same enzymes are involved in catalysing normal meiotic resection, they are noticeably less able to compensate for Exo1 during meiosis than in other phases of the cell cycle. Indeed, a recent study of meiotic resection by Zakharyevich et al. [61] demonstrated that the absence of Sgs1 does not have any significant effect upon meiotic resection tract lengths. Therefore, the most likely candidates are the structure-specific endonuclease Mre11 and/or Sae2 (both of which are required for the initial endonucleolytic cleavage event that releases Spo11 following DSB formation [62-68]). In support of this idea, strains containing mutations in SAE2 and MRE11 have been shown to exhibit resection defects at a VDE break $[53,68,69]$

\subsection{DNA synthesis and Exo1 may collaborate in the creation of heteroduplex DNA}

While Exo1 was shown to contribute to both gene conversion and resection at HIS4 in this study, there did not appear to be a one-to-one correlation. Specifically, gene conversion tracts extended much further than resection tracts, implying that DNA synthesis commonly takes place beyond the point reached by resection before the initial strand invasion event. Although this finding contradicts a previous study at the $A R G 4$ locus in which resection and gene conversion gradients were shown to be 
similar [4], it is in accord with the lengths of meiotic recombination-related DNA synthesis observed by Terasawa et al. [70]. By monitoring the incorporation of thymidine analogues during meiosis, synthesis tracts associated with a crossover were measured at $1.5 \mathrm{~kb}-1.9 \mathrm{~kb}$, lengths far in excess of those estimated to occur during resection $[4,35,58$; this study]. We cannot rule out the possibility that rapid turnover of longer resection tracts prevents these intermediates from being detected. However, the apparent disparity between the amount of DNA resected and DNA synthesised supports previous observations implying that it is the extent of heteroduplex made by the combination of DNA synthesis and second-end capture that determines the length of hDNA formed during meiosis, rather than the length of ssDNA in the first SEI [6, 51, 71, 72] (Figure 5).

Nonetheless, Exo1 evidently influences hDNA tract length in some manner as its absence results in significantly reduced amounts of gene conversion. If extensive synthesis past the initial resection point occurs, this may result in the formation of DNA flaps following capture by the resected strand on the opposite side of the DSB. We suggest that Exo1 acts either to remove these flaps or to catalyse a second phase of resection as DNA synthesis proceeds (Figure 5). Such a nucleolytic activity may not be detectable using our assay because it would occur within the context of dsDNA. This 5' end removal would allow the DNA synthesised using the homologous chromosome as a template to be incorporated into heteroduplex DNA on the chromatid that received the DSB, thereby enabling conversion tracts to extend beyond the initial resection (Figure 5). A similar role for Exo1 was previously postulated by Abdullah et al.[73] and such a function fits well with the hDNA extension model proposed by Maloisel et al.[72]. When Exo1 is absent, some limited secondary resection may be catalysed by an alternative nuclease. This alternative $5^{\prime}$ processing mechanism may also account for the observation that exo1-D173A tetrads exhibited a lower level of non-Mendelian segregation at the his4-xho allele than was observed in exol $\Delta$ cells, as substrate binding by the nucleolytically defective protein could reduce the ability of any substitute nuclease to access the DNA end.

It remains to be determined whether this second phase of resection usually occurs coordinately as DNA synthesis proceeds or later, following the displacement of the 
synthesised DNA and partial strand annealing (Figure 5). If synthesis and resection are generally coordinated, it may be that synthesis itself is reduced in the absence of Exo1. Alternatively, the same amount of nascent DNA may be produced but upon capture of the second end, a 3' flap could form [73]. Removal of this $3^{\prime}$ flap rather than assimilation of the DNA into the heteroduplex would thus result in a reduced hDNA tract. Similar $3^{\prime}$ flapped substrates have been shown to be an ideal substrate for the Mus81/Mms4 complex [74] and indeed a minor role for Mms4 in the removal of such flaps has been proposed previously to account for the increased gene conversion observed in $m m s 4 \Delta$ strains $[18,19]$. Physical analysis has also implicated Mus81/Mms4 in resolving aberrant recombination intermediates during meiosis [75, 76].

\subsection{A structural role for Exo1 in crossover promotion}

The maintenance of crossing-over in exol-D173A meiosis compared to exol $\Delta$, despite equivalent defects in resection and hDNA formation, argues that relatively short resection tracts remain largely proficient for strand invasion at most loci. Similar observations have been made previously at mitotic DSBs [32, 33]. Furthermore, it can be argued that dHJ formation is also largely unaffected by the reduction in nucleolytic processing. In light of this and the finding that the non-catalytic function of Exo1 appears to be most important when short hDNA tracts have occurred, we suggest that Exo1 is required to stabilise either the strand invasion structure or the dHJ intermediate, allowing it to be resolved as a crossover (Figure 5). A late role for Exo1 fits well with observations from $\mathrm{Exol}^{-/}$mice in which synapsis occurs normally but chiasmata are not maintained [36, 37]. The finding that crossing-over is only maintained at levels intermediate between wild-type and exol $\Delta$ strains in some intervals suggests a locus-specific requirement for the nucleolytic activity of Exo1 in some regions of the genome. The basis for this is unclear; perhaps at some loci, more extensive resection is essential to guarantee stable strand invasion. Alternatively, these sites may be more prone to unwinding of crossover-designated intermediates than others, an activity which could be exacerbated by the shorter hDNA tracts seen in exol-D173A cells. 
Exo1 has previously been suggested to act in a nuclease-independent manner during mitotic DNA mismatch repair (MMR). This function requires Exo1 to physically interact with Mlh1 [77]. A five amino acid motif R/S-S-K-(Y/F)-F known as the Mlh1 interacting protein (MIP) box in Exo1 mediates this interaction by binding a conserved S2 motif in Mlh1 [77, 78]. The physical presence of Exo1 was proposed to be important for the stabilisation of the Mlh1 and Pms1 heterodimer, thus supporting the formation of a larger multi-protein complex involved in MMR [79]. It is therefore tempting to speculate that Exo1 may behave similarly during meiosis by supporting the formation/function of the Mlh1/Mlh3 complex and a recent physical analysis of crossing-over at the HIS4LEU2 hotspot by Zakharyevich et al. [61] supports such a conclusion. However, in the Y55 strain background, a MIP box mutant exo1-S445A F447A F448A that is defective in Mlh1 binding was found to exhibit a wild-type crossover phenotype in six genetic intervals when assessed genetically. This resulted in a wild-type spore viability (V.E. Cotton \& R.H. Borts, data not shown), arguing that this same interaction motif may not be essential for the non-catalytic function of Exo1 during crossover promotion.

\subsection{The nature of the spore death in the separation-of-function allele}

In the exol-D173A strain, an increased frequency of three-viable spore tetrads was observed compared to both wild-type and exol $\Delta$ (Figure 3). We hypothesise that these events could arise if the lengths of resection that occur are sufficient to enable strand invasion but insufficient to allow strand capture. If strand capture is unsuccessful, a half crossover and a single broken chromatid could result leading to the death of the spore inheriting the broken chromatid (Figure 5). Similar situations have been suggested to occur in the absence of the strand annealing activity of Rad52 [80] and during heteroduplex rejection of the second-end capture during homeologous recombination [81]. Given that such an event need only occur at a single DSB to cause the death of one spore within a tetrad and each cell is estimated to undergo approximately 150 DSBs per meiosis [82], only a very low frequency of these aberrant events would be required to produce the viability pattern observed in exolD173A meiosis. The differential ability of a break to undergo strand invasion and strand capture could be explained either by differing amounts of resection either side of the DSB or if the length of resection required for strand capture is greater than that 
necessary for strand invasion. Broken chromatids may similarly arise in exol $\Delta$ cells but the high levels of meiosis I non-disjunction that occur may mask this phenotype.

\subsection{Conclusions}

In conclusion, Exo1 appears to perform at least three roles during meiotic DSB repair. Firstly, it functions in the $5^{\prime}$ to $3^{\prime}$ end resection that takes place following DSB formation. Secondly, it is required for the additional removal of DNA after strand invasion which allows newly synthesised DNA to be incorporated into hDNA thus leading to gene conversion and finally, it plays a nuclease-independent role in the stabilisation of crossover-designated intermediates. In contrast to earlier models proposed to explain the crossover deficit observed in exol $\Delta$ strains, it appears to be this nuclease-independent function that is the most important in terms of ensuring crossing-over at the majority of loci.

\section{Conflict of interest statement}

The authors declare that there are no conflicts of interest.

\section{Acknowledgements}

This work was funded by a BBSRC doctoral training grant studentship to REK, an MRC doctoral training grant studentship to VEC and a BBSRC grant to ASHG. RHB holds a Royal Society Wolfson Research Merit Award. We thank Neil Hunter for sharing data with us prior to publication, Michael Lichten for helpful discussions and Yaroslav Terentyev and Adam Hodgson for technical assistance. We also thank Neil Hunter and Eric Alani for providing reagents.

\section{References}

[1] S. Keeney, C.N. Giroux, N. Kleckner, Meiosis-specific DNA double-strand breaks are catalyzed by Spo11, a member of a widely conserved protein family, Cell, 88 (1997) 375-384.

[2] M.J. Neale, J. Pan, S. Keeney, Endonucleolytic processing of covalent proteinlinked DNA double-strand breaks, Nature, 436 (2005) 1053-1057.

[3] H. Sun, D. Treco, N.P. Schultes, J.W. Szostak, Double-strand breaks at an initiation site for meiotic gene conversion, Nature, 338 (1989) 87-90.

[4] H. Sun, D. Treco, J.W. Szostak, Extensive 3'-overhanging, single-stranded DNA associated with the meiosis-specific double-strand breaks at the ARG4 recombination initiation site, Cell, 64 (1991) 1155-1161. 
[5] S.L. Gasior, A.K. Wong, Y. Kora, A. Shinohara, D.K. Bishop, Rad52 associates with RPA and functions with Rad55 and Rad57 to assemble meiotic recombination complexes, Genes Dev, 12 (1998) 2208-2221.

[6] N. Hunter, N. Kleckner, The single-end invasion: An asymmetric intermediate at the double-strand break to double-Holliday junction transition of meiotic recombination, Cell, 106 (2001) 59-70.

[7] A. Schwacha, N. Kleckner, Identification of double Holliday junctions as intermediates in meiotic recombination, Cell, 83 (1995) 783-791.

[8] A. Schwacha, N. Kleckner, Identification of joint molecules that form frequently between homologs but rarely between sister chromatids during yeast meiosis, Cell, 76 (1994) 51-63.

[9] N. Hunter, Meiotic recombination, in: A. Aguilera, R. Rothstein (Eds.)

Molecular Genetics of Recombination, Springer-Verlag, Heidelberg, 2007, pp. 381-442.

[10] P. Ross-Macdonald, G.S. Roeder, Mutation of a meiosis-specific MutS homolog decreases crossing over but not mismatch correction, Cell, 79 (1994) 1069-1080.

[11] N.M. Hollingsworth, L. Ponte, C. Halsey, MSH5, a novel MutS homolog, facilitates meiotic reciprocal recombination between homologs in Saccharomyces cerevisiae but not mismatch repair, Genes Dev, 9 (1995) 1728-1739.

[12] T. Snowden, S. Acharya, C. Butz, M. Berardini, R. Fishel, hMSH4-hMSH5 recognizes Holliday junctions and forms a meiosis-specific sliding clamp that embraces homologous chromosomes, Mol Cell, 15 (2004) 437-451.

[13] N. Hunter, R.H. Borts, Mlh1 is unique among mismatch repair proteins in its ability to promote crossing-over during meiosis, Genes Dev, 11 (1997) 15731582.

[14] T.F. Wang, N. Kleckner, N. Hunter, Functional specificity of MutL homologs in yeast: evidence for three Mlh1-based heterocomplexes with distinct roles during meiosis in recombination and mismatch correction, Proc Natl Acad Sci USA, 96 (1999) 13914-13919.

[15] S.M. Baker, A.W. Plug, T.A. Prolla, C.E. Bronner, A.C. Harris, X. Yao, D.M. Christie, C. Monell, N. Arnheim, A. Bradley, T. Ashley, R.M. Liskay, Involvement of mouse Mlh1 in DNA mismatch repair and meiotic crossing over, Nat Genet, 13 (1996) 336-342.

[16] V.E. Cotton, E.R. Hoffmann, R.H. Borts, Distinct regulation of Mlh1p heterodimers in meiosis and mitosis in Saccharomyces cerevisiae, Genetics, 185 (2010) 459-467.

[17] K.T. Nishant, A.J. Plys, E. Alani, A mutation in the putative MLH3 endonuclease domain confers a defect in both mismatch repair and meiosis in Saccharomyces cerevisiae, Genetics, 179 (2008) 747-755.

[18] T. de los Santos, J. Loidl, B. Larkin, N.M. Hollingsworth, A role for MMS4 in the processing of recombination intermediates during meiosis in Saccharomyces cerevisiae, Genetics, 159 (2001) 1511-1525.

[19] T. de los Santos, N. Hunter, C. Lee, B. Larkin, J. Loidl, N.M. Hollingsworth, The Mus81/Mms4 endonuclease acts independently of double-Holliday junction resolution to promote a distinct subset of crossovers during meiosis in budding yeast, Genetics, 164 (2003) 81-94.

[20] J.L. Argueso, J. Wanat, Z. Gemici, E. Alani, Competing crossover pathways act during meiosis in Saccharomyces cerevisiae, Genetics, 168 (2004) 1805-1816. 
[21] F. Paques, J.E. Haber, Multiple pathways of recombination induced by double-strand breaks in Saccharomyces cerevisiae, Microbiol Mol Biol Rev, 63 (1999) 349-404.

[22] T. Allers, M. Lichten, Differential timing and control of noncrossover and crossover recombination during meiosis, Cell, 106 (2001) 47-57.

[23] P.T. Tran, N. Erdeniz, S. Dudley, R.M. Liskay, Characterization of nucleasedependent functions of Exo1p in Saccharomyces cerevisiae, DNA Repair (Amst), 1 (2002) 895-912.

[24] P. Szankasi, G.R. Smith, A role for Exonuclease I from S. pombe in mutation avoidance and mismatch correction, Science, 267 (1995) 1166-1169.

[25] H. Tsubouchi, H. Ogawa, Exo1 roles for repair of DNA double-strand breaks and meiotic crossing over in Saccharomyces cerevisiae, Mol Biol Cell, 11 (2000) 2221-2233.

[26] S. Chu, J. DeRisi, M. Eisen, J. Mulholland, D. Botstein, P.O. Brown, I. Herskowitz, The transcriptional program of sporulation in budding yeast, Science, 282 (1998) 699-705.

[27] F.A. Digilio, A. Pannuti, J.C. Lucchesi, M. Furia, L. Polito, Tosca: A Drosphila gene encoding a nuclease specifically expressed in the female germline, Dev Biol, 178 (1996) 90-100.

[28] B. Lee, M. Shannon, L. Stubbs, D. Wilson, 3rd, Expression specificity of the mouse Exonuclease 1 (mExo1) gene, Nucl Acids Res, 27 (1999) 4114-4120.

[29] D.T. Kirkpatrick, J.R. Ferguson, T.D. Petes, L.S. Symington, Decreased meiotic intergenic recombination and increased meiosis I nondisjunction in exo1 mutants of Saccharomyces cerevisiae, Genetics, 156 (2000) 1549-1557.

[30] K.A. Khazanehdari, R.H. Borts, EXO1 and MSH4 differentially affect crossingover and segregation, Chromosoma, 109 (2000) 94-102.

[31] R.H. Borts, S.R. Chambers, M.F. Abdullah, The many faces of mismatch repair in meiosis, Mutat Res, 451 (2000) 129-150.

[32] Z. Zhu, W.-H. Chung, E.Y. Shim, S.E. Lee, G. Ira, Sgs1 helicase and two nucleases Dna2 and Exo1 resect DNA double-strand break ends, Cell, 134 (2008) 981-994.

[33] E.P. Mimitou, L.S. Symington, Sae2, Exo1 and Sgs1 collaborate in DNA double-strand break processing, Nature, 455 (2008) 770-774.

[34] N. Manfrini, I. Guerini, A. Citterio, G. Lucchini, M.P. Longhese, Processing of meiotic DNA double strand breaks requires cyclin-dependent kinase and multiple nucleases, J Biol Chem, 285 (2010) 11628-11637.

[35] D.K. Bishop, D. Park, L. Xu, N. Kleckner, DMC1: A meiosis-specific yeast homolog of $E$. coli recA required for recombination, synaptonemal complex formation, and cell cycle progression, Cell, 69 (1992) 439-456.

[36] R. Kan, X. Sun, N.K. Kolas, E. Avdievich, B. Kneitz, W. Edelmann, P.E. Cohen, Comparative analysis of meiotic progression in female mice bearing mutations in genes of the DNA mismatch repair pathway, Biol Reprod, 78 (2008) 462-471. [37] K. Wei, A.B. Clark, E. Wong, M.F. Kane, D.J. Mazur, T. Parris, N.K. Kolas, R. Russell, H. Hou, Jr., B. Kneitz, G. Yang, T.A. Kunkel, R.D. Kolodner, P.E. Cohen, W. Edelmann, Inactivation of Exonuclease 1 in mice results in DNA mismatch repair defects, increased cancer susceptibility, and male and female sterility, Genes Dev, 17 (2003) 603-614.

[38] S.M. Kane, R. Roth, Carbohydrate metabolism during ascospore development in yeast, J Bacteriol, 118 (1974) 8-14. 
[39] E. Martini, R.L. Diaz, N. Hunter, S. Keeney, Crossover homeostasis in yeast meiosis, Cell, 126 (2006) 285-295.

[40] R.H. Borts, M. Lichten, J.E. Haber, Analysis of meiosis-defective mutations in yeast by physical monitoring of recombination, Genetics, 113 (1986) 551-567. [41] A. Nicolas, D. Treco, N.P. Schultes, J.W. Szostak, An initiation site for meiotic gene conversion in the yeast Saccharomyces cerevisiae, Nature, 338 (1989) 3539.

[42] E.R. Hoffmann, E. Eriksson, B.J. Herbert, R.H. Borts, $M L H 1$ and $M S H 2$ promote the symmetry of double-strand break repair events at the HIS4 hotspot in Saccharomyces cerevisiae, Genetics, 169 (2005) 1291-1303.

[43] E. Alani, R. Padmore, N. Kleckner, Analysis of wild-type and rad50 mutants of yeast suggests an intimate relationship between meiotic chromosome synapsis and recombination, Cell, 61 (1990) 419-436.

[44] A. Wach, A. Brachat, R. Poehlmann, P. Philippsen, New heterologous modules for classical or PCR-based gene disruptions in Saccharomyces cerevisiae, Yeast, 10 (1994) 1793-1808.

[45] N. Erdeniz, U.H. Mortensen, R. Rothstein, Cloning-free PCR-based allele replacement methods, Genome Res, 7 (1997) 1174-1183.

[46] T. Sokolsky, E. Alani, EXO1 and MSH6 are high-copy suppressors of conditional mutations in the MSH2 mismatch repair gene of Saccharomyces cerevisiae, Genetics, 155 (2000) 589-599.

[47] V.E. Cotton, E.R. Hoffmann, M.F. Abdullah, R.H. Borts, Interaction of genetic and environmental factors in Saccharomyces cerevisiae meiosis: The devil is in the details, in: S. Keeney (Ed.) Meiosis: Volume 1, Molecular and Genetic Methods, Humana Press, Totowa, 2009, pp. 3-20.

[48] Q. Fan, F. Xu, T.D. Petes, Meiosis-specific double-strand DNA breaks at the HIS4 recombination hot spot in the yeast Saccharomyces cerevisiae: control in cis and trans, Mol Cell Biol, 15 (1995) 1679-1688.

[49] M.F.F. Abdullah, R.H. Borts, Meiotic recombination frequencies are affected by nutritional states in Saccharomyces cerevisiae, Proc Natl Acad Sci USA, 98 (2001) 14524-14529.

[50] D.D. Perkins, Biochemical mutants in the smut fungus Ustilago maydis, Genetics, 34 (1949) 607-626.

[51] L. Jessop, T. Allers, M. Lichten, Infrequent co-conversion of markers flanking a meiotic recombination initiation site in Saccharomyces cerevisiae, Genetics, 169 (2005) 1353-1367.

[52] R. Sokal, F. Rohlf, Biometry: The principles and practice of statistics in biological research, 1st Edition. W.H. Freeman and Company, NY., (1969). [53] A. Hodgson, Y. Terentyev, R.A. Johnson, A. Bishop-Bailey, A.S.H. Goldman, Mre11 and Exo1 contribute to the initiation and processivity of resection at meiotic double-strand breaks made independently of Spo11, Submitted, (2010). [54] T. Allers, M. Lichten, A method for preparing genomic DNA that restrains branch migration of Holliday junctions, Nucl Acids Res, 28 (2000) e6.

[55] T. Allers, M. Lichten, Intermediates of yeast meiotic recombination contain heteroduplex DNA, Mol Cell, 8 (2001) 225-231.

[56] R. Padmore, L. Cao, N. Kleckner, Temporal comparison of recombination and synaptonemal complex formation during meiosis in S. cerevisiae, Cell, 66 (1991) 1239-1256. 
[57] D.K. Nag, T.D. Petes, Physical detection of heteroduplexes during meiotic recombination in the yeast Saccharomyces cerevisiae, Mol Cell Biol, 13 (1993) 2324-2331.

[58] M. Vedel, A. Nicolas, CYS3, a hotspot of meiotic recombination in Saccharomyces cerevisiae: Effects of heterozygosity and mismatch repair functions on gene conversion and recombination intermediates, Genetics, 151 (1999) 1245-1259.

[59] A.C.-H. Chan, R.H. Borts, E. Hoffmann, Temperature-dependent modulation of chromosome segregation in msh4 mutants of budding yeast, PLoS ONE, 4 (2009) e7284.

[60] N. Joshi, A. Barot, C. Jamison, G.V. Borner, Pch2 links chromosome axis remodeling at future crossover sites and crossover distribution during yeast meiosis, PLoS Genet, 5 (2009) e1000557.

[61] K. Zakharyevich, Y. Ma, S. Tang, P.Y.-H. Hwang, S. Boiteux, N. Hunter, Temporally and biochemically distinct activities of Exo1 during meiosis promote double-strand-break resection and resolution of double-Holliday junctions into crossovers, Mol Cell, in press.

[62] K. Nairz, F. Klein, mre11S - a yeast mutation that blocks double-strand-break processing and permits nonhomologous synapsis in meiosis, Genes Dev, 11 (1997) 2272-2290.

[63] M. Furuse, Y. Nagase, H. Tsubouchi, K. Murakami-Murofushi, T. Shibata, K. Ohta, Distinct roles of two separable in vitro activities of yeast Mre11 in mitotic and meiotic recombination, Embo J, 17 (1998) 6412-6425.

[64] H. Tsubouchi, H. Ogawa, A novel Mre11 mutation impairs processing of double-strand breaks of DNA during both mitosis and meiosis, Mol Cell Biol, 18 (1998) 260-268.

[65] S. Moreau, J.R. Ferguson, L.S. Symington, The nuclease activity of Mre11 Is required for meiosis but not for mating type switching, end joining, or telomere maintenance, Mol Cell Biol, 19 (1999) 556-566.

[66] A. McKee, N. Kleckner, A general method for identifying recessive diploidspecific mutations in Saccharomyces cerevisiae, its application to the isolation of mutants blocked at intermediate stages of meiotic prophase and characterization of a new gene SAE2, Genetics, 146 (1997) 797-816.

[67] S. Prinz, A. Amon, F. Klein, Isolation of COM1, a new gene required to complete meiotic double-strand break-induced recombination in Saccharomyces cerevisiae, Genetics, 146 (1997) 781-795.

[68] M.J. Neale, M. Ramachandran, E. Trelles-Sticken, H. Scherthan, A.S.H. Goldman, Wild-type levels of Spo11-induced DSBs are required for normal single-strand resection during meiosis, Mol Cell, 9 (2002) 835-846.

[69] T. Fukuda, S. Nogami, Y. Ohya, VDE-initiated intein homing in Saccharomyces cerevisiae proceeds in a meiotic recombination-like manner, Genes to Cells, 8 (2003) 587-602.

[70] M. Terasawa, H. Ogawa, Y. Tsukamoto, M. Shinohara, K. Shirahige, N. Kleckner, T. Ogawa, Meiotic recombination-related DNA synthesis and its implications for cross-over and non-cross-over recombinant formation, Proc Natl Acad Sci USA, 104 (2007) 5965-5970.

[71] J.D. Merker, M. Dominska, T.D. Petes, Patterns of heteroduplex formation associated with the initiation of meiotic recombination in the yeast Saccharomyces cerevisiae, Genetics, 165 (2003) 47-63. 
[72] L. Maloisel, J. Bhargava, G.S. Roeder, A role for DNA polymerase delta in gene conversion and crossing over during meiosis in Saccharomyces cerevisiae, Genetics, 167 (2004) 1133-1142.

[73] M.F. Abdullah, E.R. Hoffmann, V.E. Cotton, R.H. Borts, A role for the MutL homologue $M L H 2$ in controlling heteroduplex formation and in regulating between two different crossover pathways in budding yeast, Cytogenet Genome Res, 107 (2004) 180-190.

[74] K.T. Ehmsen, W.-D. Heyer, A junction branch point adjacent to a DNA backbone nick directs substrate cleavage by Saccharomyces cerevisiae Mus81Mms4, Nucl Acids Res, 37 (2009) 2026-2036.

[75] S.D. Oh, J.P. Lao, A.F. Taylor, G.R. Smith, N. Hunter, RecQ helicase, Sgs1, and XPF family endonuclease, Mus81-Mms4, resolve aberrant joint molecules during meiotic recombination, Mol Cell, 31 (2008) 324-336.

[76] L. Jessop, M. Lichten, Mus81/Mms4 endonuclease and Sgs1 helicase collaborate to ensure proper recombination intermediate metabolism during meiosis, Mol Cell, 31 (2008) 313-323.

[77] P.T. Tran, J.P. Fey, N. Erdeniz, L. Gellon, S. Boiteux, R.M. Liskay, A mutation in EXO1 defines separable roles in DNA mismatch repair and post-replication repair, DNA Repair (Amst), 6 (2007) 1572-1583.

[78] C. Dherin, E. Gueneau, M. Francin, M. Nunez, S. Miron, S.E. Liberti, L.J. Rasmussen, S. Zinn-Justin, B. Gilquin, J.-B. Charbonnier, S. Boiteux,

Characterization of a highly conserved binding site of Mlh1 required for Exonuclease I-dependent mismatch repair, Mol Cell Biol, 29 (2009) 907-918. [79] N.S. Amin, M.N. Nguyen, S. Oh, R.D. Kolodner, exo1-Dependent mutator mutations: model system for studying functional interactions in mismatch repair, Mol Cell Biol, 21 (2001) 5142-5155.

[80] J.P. Lao, S.D. Oh, M. Shinohara, A. Shinohara, N. Hunter, Rad52 promotes postinvasion steps of meiotic double-strand-break repair, Mol Cell, 29 (2008) 517-524.

[81] S.R. Chambers, N. Hunter, E.J. Louis, R.H. Borts, The mismatch repair system reduces meiotic homeologous recombination and stimulates recombinationdependent chromosome loss, Mol Cell Biol, 16 (1996) 6110-6120.

[82] C. Buhler, V. Borde, M. Lichten, Mapping meiotic single-strand DNA reveals a new landscape of DNA double-strand breaks in Saccharomyces cerevisiae, PLoS Biol, 5 (2007) e324. 


\section{Figure 1 - Resection analysis at HIS4.}

(A) Schematic diagram indicating the approximate locations of the resection assay target sites used with respect to the HIS4 hotspot. PCR primer pairs were designed to anneal either side of these sites. Amplification was only possible from these primers when the restriction site indicated was present in single-stranded form and thus protected from restriction endonuclease cleavage. Each pair was used in conjunction with a second pair of primers at the rDNA locus that served to measure the total amount of DNA within the reaction. (B) Non-cumulative curves describing the formation of DSBs at HIS4 and the production of ssDNA at approximately $0.5 \mathrm{~kb}, 0.8$ $\mathrm{kb}, 1.25 \mathrm{~kb}$ and $2 \mathrm{~kb}$ from the HIS4 hotspot in wild-type (RKD51), exo1 $($ RKD52) and exo1-D173A (RKD55) meiotic time course experiments. Each data point plotted is the average of two independent time courses. Bars indicate the range observed.

(C) The non-cumulative data for the wild-type and exo1 $\Delta$ time courses presented were converted to cumulative curves as described in Methods 2.6. (D) The cumulative amount of ssDNA produced by 12 hours was then divided by the total amount of DSBs formed in order to estimate the overall proportion of DSBs resected as far as each target site during the 12 hour period monitored. The proportions observed are plotted with respect to the HIS4 start codon. For each genotype, the data presented is the mean of two independent time courses. Bars indicate the range observed.

\section{Figure 2 - The effect of EXO1 deletion on the HIS4 gene conversion gradient}

Following tetrad dissection, gene conversion was measured at two alleles situated 96 bp and 1,688 bp from the HIS4 start codon (approximately $0.4 \mathrm{~kb}$ and $2 \mathrm{~kb}$ from the HIS4 hotspot). Gene conversions result from the presence of mismatches within heteroduplex DNA (hDNA) formed during recombination. In fungi, the frequency of gene conversion is known to decrease with increasing distance from the DSB and this is termed a conversion gradient [31]. In the absence of EXO1, gene conversion is significantly reduced at both alleles. The wild-type data was derived from crosses RK358 x RK392 and RK385 x RK392. The corresponding exol $\Delta$ strains were RK359 x RK394 and RK387 x RK394.

Figure 3 - Genetic analysis in wild-type, exo1 $\Delta$ and exo1-D173A strains 
(A) Schematic diagram showing the approximate chromosomal locations of markers used in genetic analysis (drawings not to scale). (B) Patterns of spore viability obtained in wild-type (RK358 x RK392), exo1 4 (RK359 x RK394) and exo1-D173A (RK399 x RK425) indicating the proportions of viable spores per tetrad. The total number of tetrads dissected for each strain is indicated and the overall viability given in parentheses. (C) Measurements of map distances in six intervals were calculated using the formula of Perkins et al. [49]. Comparisons between recombination classes were made by G-test and statistically significant differences $(\mathrm{p}<0.0256)$ are indicated by an asterisk. (D) Rates of chromosome III meiosis I non-disjunction were assessed by monitoring the proportion of non-mating spores produced. Statistical comparisons were made as above and significant differences are indicated by asterisks.

\section{Figure 4 - Schematic diagram of HIS4 marker configurations used in random spore analysis}

In order to assess recombination associated with the HIS4 hotspot, two diploids (A and B) were used containing different pairs of his 4 hetero-alleles. The configurations of markers on the two parental chromosomes (P1 and P2) in these diploids are illustrated. The positions of the his4-xho, his4-cla and his4-bgl alleles are given relative to the HIS4 start codon and the orientations of the flanking nourseothricin (NAT) and hygromycin B $(H P H)$ drug-resistance cassettes are shown. The NAT and HPH cassettes are located 3,806 bp downstream and 5,130 bp upstream of the HIS4 start codon respectively. The HIS4 hotspot breakpoint is located approximately 300 bp upstream of the start codon and is indicated by the arrows. The strains used were RKD62 to RKD79.

\section{Figure 5 - Model demonstrating multiple roles for Exo1 during meiotic recombination.}

(A) Following DSB formation, Exo1 acts to resect the DNA ends in a 5' to $3^{\prime}$ direction. When Exo1 nuclease activity is absent, limited resection may be catalysed by Mre11 and/or Sae2. The overhanging 3' strands can then begin to interact with the homologous chromosome and a D-loop is produced upon invasion. If a break is to be repaired as a non-crossover, DNA synthesis and strand displacement will follow. (B) Along the crossover pathway, the D-loop requires stabilisation by proteins such as 
Msh4/Msh5 (shown in orange). If Exo1 also performs an early stabilising function, its absence may lead to displacement of the SEI, collapsing the D-loop. A noncrossover can be formed by SDSA. (C) With a stable SEI, extensive DNA synthesis then takes place, which may or may not be coordinated with processive resection. (D) The synthesised end is eventually displaced and attempts to anneal to the strand uncovered by resection on the opposite side of the break. (E) If there is insufficient resection for this annealing to occur, a half crossover and a single broken chromatid could result. (F) Upon successful annealing, if DNA synthesis and resection do not occur at the same rate, DNA flaps could be formed from displacement of the unresected region. $(G)$ These flaps normally require Exo1 for removal, allowing $\mathrm{dHJ}$ to form and undergo subsequent resolution as crossovers. $(\mathrm{H})$ When Exo1 nuclease activity is absent, $3^{\prime}$ flaps could be produced that may serve as substrates for Mus81/Mms4 (indicated by green triangle). This would then permit ligation and completion of the $\mathrm{dHJ}$. (I) If instead of/in addition to an early stabilising role, the nuclease-independent function of Exo1 (shown in purple) acts to stabilise the dHJ structure, crossovers would form as normal in exo1-D173A. (J) Without this stabilising activity in exol $\Delta$, crossovers would not be produced. 
Table 1 - Haploid yeast strains

\begin{tabular}{|c|c|}
\hline Strain & Genotype $^{\mathrm{a}}$ \\
\hline RK358 & his4-xho MAT $\alpha$ ade1-1 lys5-p cyh2-z CEN8:URA3 arg4-nsp \\
\hline RK359 & his4-xho MAT $\alpha$ ade1-1 lys5-p cyh2-z CEN8:URA3 arg4-nsp exo1 $\triangle:$ KanMX4 \\
\hline RK385 & his4-bgl MAT $\alpha$ ade1-1 lys5-p cyh2-z CEN8:URA3 arg4-nsp \\
\hline RK387 & his4-bgl MAT $\alpha$ ade 1-1 lys5-p cyh2-z CEN8:URA3 arg4-nsp exo1 $\triangle:: K a n M X 4$ \\
\hline RK392 & leu2-r MATa ade1-1 met13-b trp5-s \\
\hline RK394 & leu2-r MATa ade1-1 met13-b trp5-s exo1 $\Delta::$ KanMX4 \\
\hline RK399 & his4-xho MAT $\alpha$ ade1-1 lys5-p cyh2-z CEN8:URA3 arg4-nsp exo1-D173A \\
\hline RK425 & leu2-r MATa ade1-1 met13-b trp5-s exo1-D173A \\
\hline
\end{tabular}

${ }^{a}$ All strains are in the SK1 background and are also ho::LYS2 lys 2 ura3 


\section{Table 2 - Diploid yeast strains}

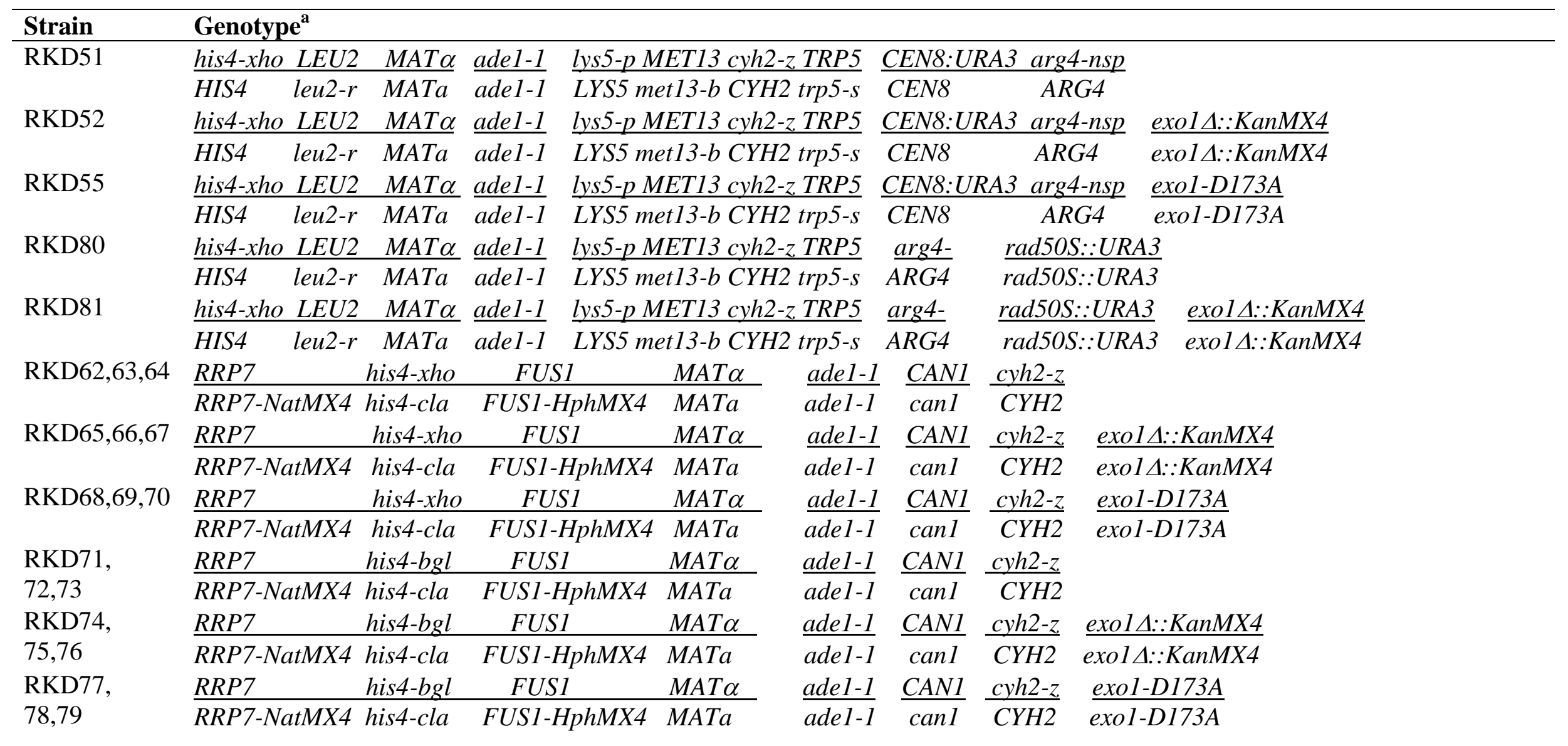

${ }^{a}$ All strains are in the SK1 strain background and are also ho::LYS2 lys2 ura3. Where multiple strain numbers refer to the same genotype, each originates from an independently isolated diploid colony. 
Table 3 - Oligonucleotide sequences used for quantitative PCR analysis

\begin{tabular}{ll}
\hline Description & Sequence (5' to 3') \\
\hline 5' at rDNA locus & ATCAGCTTGCGTTGATTACG \\
3' at rDNA locus & GTTGCCCCCTTCTCTAAGC \\
5' of NheI site (238bp from HIS4) & ATTGGTGGCTTTGTCCTTGC \\
3' of NheI site (238bp from HIS4) & CAAGTGTTCGGCTGTTTTAGC \\
5' of ClaI site (532bp from HIS4) & GAGCGTTGTCTAGGGTTGGT \\
3' of Cla I site (532bp from HIS4) & TCACCCTTGATCCAGATTTCA \\
5' of AatII site (955bp from HIS4) & GGCTGCCGATTTGTTCTACT \\
3' of AatII site (955bp from HIS4) & TGGCTTAGCATCACCTTTCC \\
5' of BglII site (1688bp from HIS4) & CGCTTCCAAGATTGTTCTACC \\
3' of BglII site (1688bp from HIS4) & ACATACATTTTGGCGGCAGT
\end{tabular}


Table 4 - The effect of Exo1 on non-Mendelian segregation

\begin{tabular}{|c|c|c|c|c|c|c|c|c|c|c|}
\hline \multirow[b]{2}{*}{ Genotype } & & \multicolumn{9}{|c|}{ Allele } \\
\hline & & his4-xho & his4-bgl & leu2-r & $M A T$ & lys5-p & met13-b & $\operatorname{cyh} 2-z$ & $\operatorname{trp5-s}$ & $\begin{array}{c}\arg 4- \\
\text { nsp }\end{array}$ \\
\hline Wild-type & $\% \mathrm{NMS}^{\mathrm{a}}$ & $29.2^{\dagger}$ & $11.2^{\dagger}$ & $3.6^{\dagger}$ & 0.9 & 1.4 & 1.8 & 0.7 & 1.3 & $6.1^{\dagger}$ \\
\hline & $\begin{array}{c}\text { (NMS/total } \\
\text { tetrads) }\end{array}$ & $(275 / 941)$ & $(38 / 338)$ & $(34 / 941)$ & $(8 / 941)$ & $(13 / 941)$ & $(17 / 941)$ & $(7 / 941)$ & $(12 / 941)$ & $(58 / 941)$ \\
\hline exols & $\% \mathrm{NMS}^{\mathrm{a}}$ & $23.6^{*}$ & $2.5^{*}$ & $1.1^{*}$ & 0.2 & 0.9 & 1.0 & 0.5 & 0.3 & $2.9^{*}$ \\
\hline & $\begin{array}{c}\text { (NMS/total } \\
\text { tetrads) }\end{array}$ & $(209 / 885)$ & $(3 / 118)$ & $(10 / 885)$ & $(2 / 885)$ & $(8 / 885)$ & $(9 / 885)$ & $(4 / 885)$ & $(3 / 885)$ & $(26 / 885)$ \\
\hline $\begin{array}{c}\text { exol- } \\
\text { D173A }\end{array}$ & $\% \mathrm{NMS}^{\mathrm{a}}$ & $15.4^{* \dagger}$ & $\begin{array}{c}\text { not } \\
\text { tested }\end{array}$ & $1.3^{*}$ & 0 & 1.9 & 2.5 & 0.3 & 1.6 & 5.6 \\
\hline & $\begin{array}{l}\text { (NMS/total } \\
\text { tetrads) }\end{array}$ & $(49 / 319)$ & & $(4 / 319)$ & $(0 / 319)$ & $(6 / 319)$ & $(8 / 319)$ & $(1 / 319)$ & $(5 / 319)$ & $(18 / 319)$ \\
\hline
\end{tabular}

${ }^{a}$ Comparisons were made using the G-test of homogeneity and statistically significant $(\mathrm{p}<0.0258)$ differences are indicated as follows: * significantly different from wild-type, ${ }^{\dagger}$ significantly different from exol $\Delta$. 
Table 5 - Association of prototroph formation with crossing-over at HIS4

\begin{tabular}{|c|c|c|c|c|c|c|c|}
\hline \multirow[b]{3}{*}{ Heteroalleles } & \multirow[b]{3}{*}{ Genotype } & \multicolumn{4}{|c|}{ Configuration of flanking markers } & \multirow[b]{3}{*}{ Total $^{\mathbf{a}}$} & \multirow{3}{*}{$\begin{array}{l}\text { \% Crossover } \\
\text { associated }^{b, c}\end{array}$} \\
\hline & & \multicolumn{2}{|c|}{ Parental } & \multicolumn{2}{|c|}{ Recombinant } & & \\
\hline & & $N a t^{R} H_{p h}^{R}$ & $\mathrm{Nat}^{S} \mathrm{Hph}^{S}$ & $\mathrm{Nat}^{R} \mathrm{Hph}^{S}$ & $\mathrm{Nat}^{S} \mathrm{Hph}^{\mathrm{R}}$ & & \\
\hline his4-xho/ & Wild-type & 34 & 308 & 32 & 226 & 600 & 43 \\
\hline \multirow[t]{2}{*}{ his4-cla } & exold & 43 & 320 & 34 & 203 & 600 & 39.5 \\
\hline & exo1-D173A & 17 & 245 & 22 & 316 & 600 & $56.3^{* \dagger}$ \\
\hline his4-clal & Wild-type & 123 & 24 & 447 & 5 & 599 & $75.5^{\dagger}$ \\
\hline \multirow[t]{2}{*}{ his4-bgl } & exold & 78 & 15 & 503 & 4 & 600 & $84.5^{*}$ \\
\hline & exol-D173A & 83 & 13 & 501 & 3 & 600 & $84^{*}$ \\
\hline
\end{tabular}

${ }^{a}$ For each genotype, data from three independent experiments were pooled.

${ }^{\mathrm{b}}$ The proportions of parental and recombinant spores were compared using the G-test of homogeneity and statistically significant values ( $\mathrm{p}<0.0169$, G-test of homogeneity) are indicated as follows: ${ }^{*}$ significantly different from wild-type, ${ }^{\dagger}$ significantly different from exol $\Delta$.

${ }^{c}$ All genotypes displayed a significant increase in crossover association when the his4-cla/his4-bgl heteroalleles were used compared to the his4cla/his4-bgl heteroalleles. 
Table 6 - Crossing-over between flanking markers at the HIS4 hotspot

\begin{tabular}{lccc}
\hline Genotype & $\begin{array}{c}\text { Configuration of } \\
\text { Parental }\end{array}$ & Recombinant & $\begin{array}{c}\text { Recombination } \\
\text { frequency }^{\mathbf{a}, \mathbf{b}}\end{array}$ \\
\hline Wild-type & 549 & 51 & 8.5 \\
exo14 & 568 & 32 & 5.3 \\
exo1-D173A & 558 & 42 & 7 \\
\hline
\end{tabular}

${ }^{a}$ For each genotype data from 6 independent cultures were pooled.

${ }^{\mathrm{b}}$ Recombination frequencies were calculated as: (number of recombinants/total number of colonies) x 100 . 


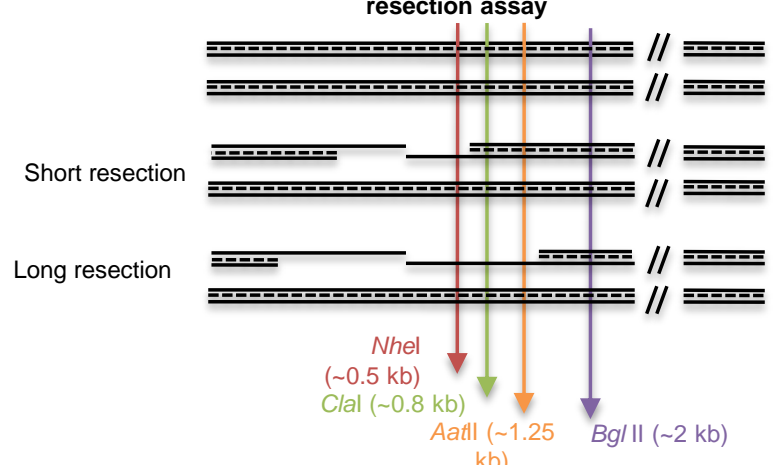

(B)

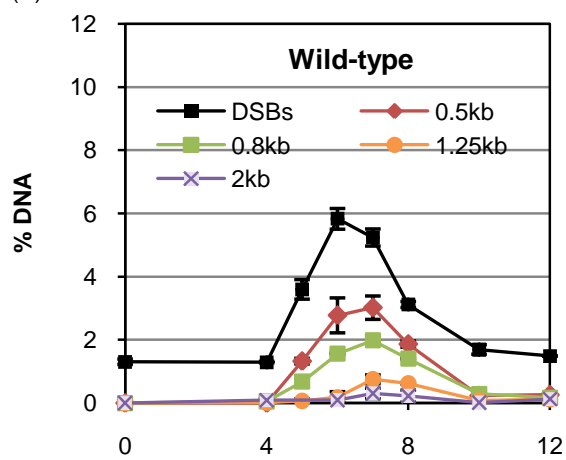

(C)
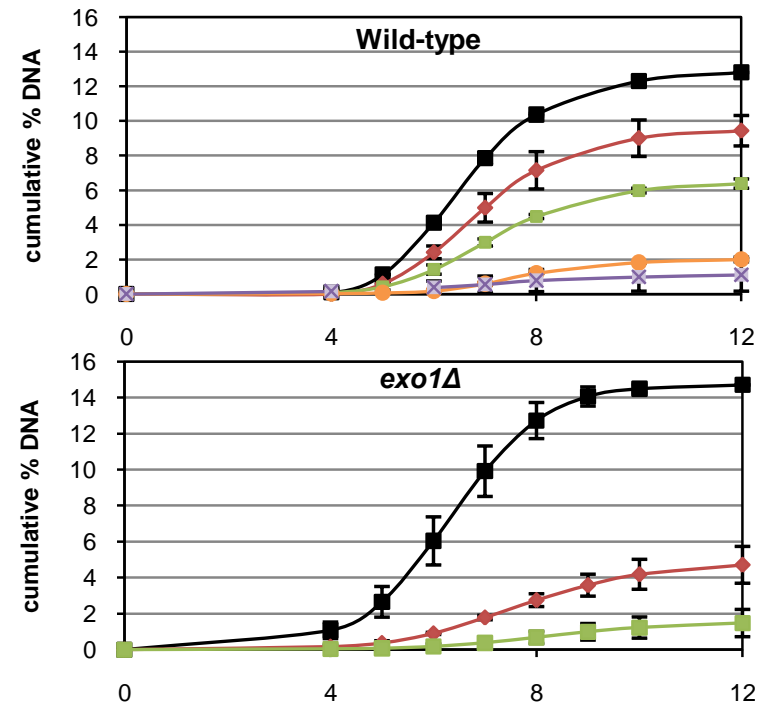

$-0.8 \mathrm{~kb}$ $\longrightarrow$ DSBs

$\longrightarrow 0.5 \mathrm{~kb}$

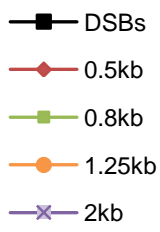

Time in sporulation medium (hours)

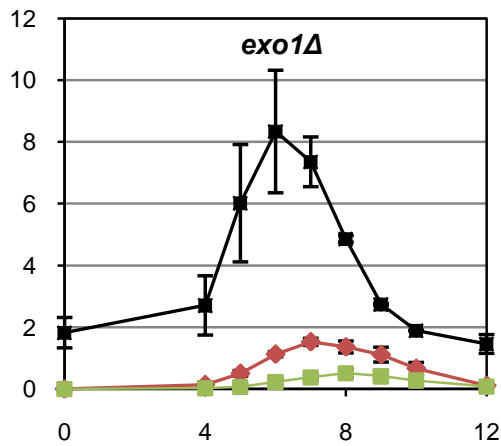

Time in sporulation medium (hours)

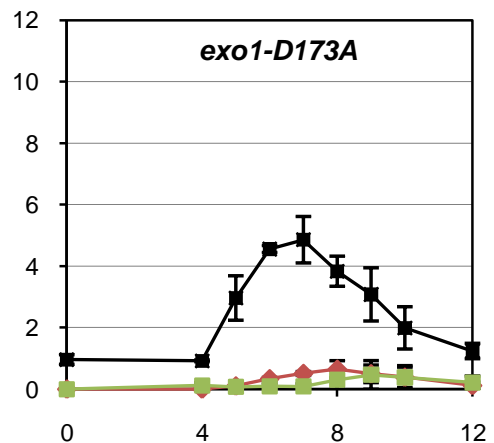

12

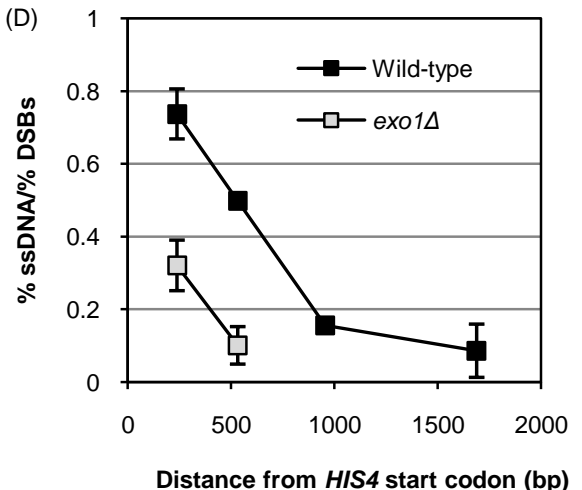

Distance from HIS4 start codon (bp) 


\section{Figure 2R}

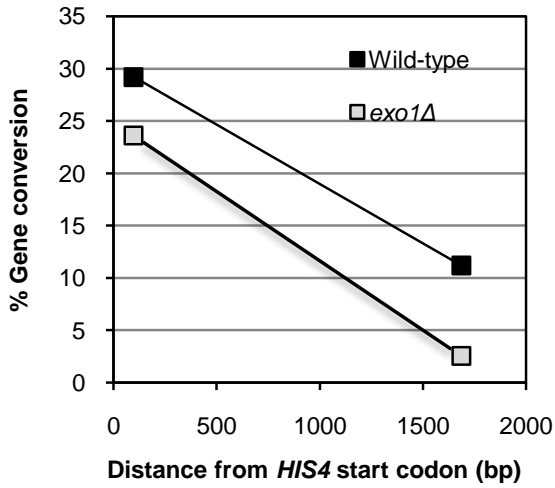


III

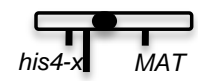

VII

leu2- $R$

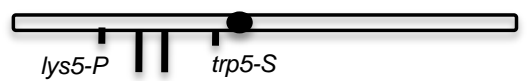

VIII

met13-Bcyh2-z

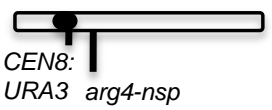

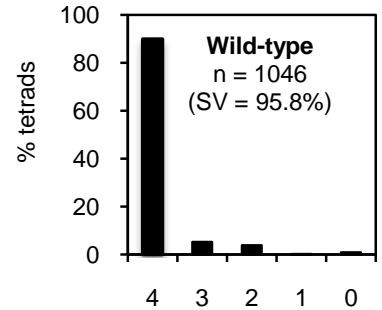

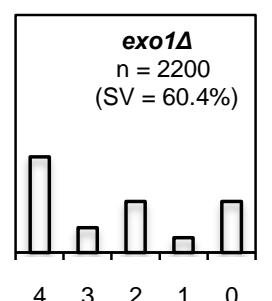

exo1-D173A

$\mathrm{n}=831$

$(\mathrm{SV}=70.2 \%)$

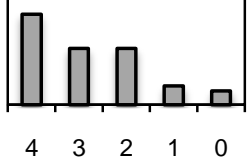

Number of viable spores per tetrad
(C)

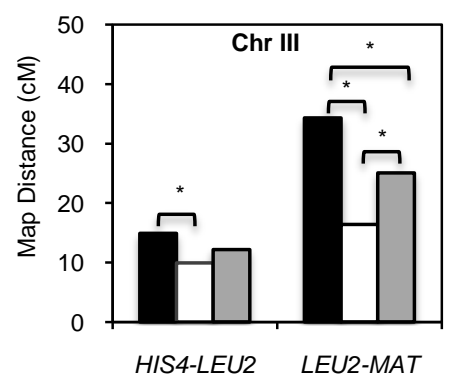

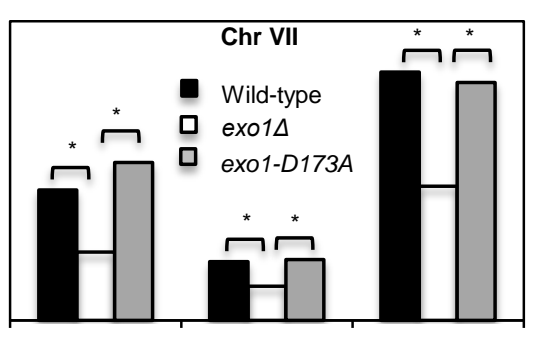

LYS5-MET13 MET13-CYH2

CYH2-TRP5
(D)

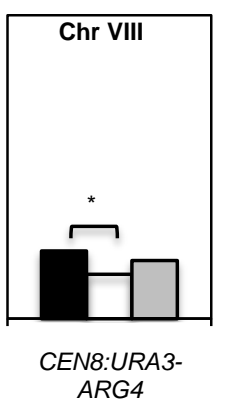

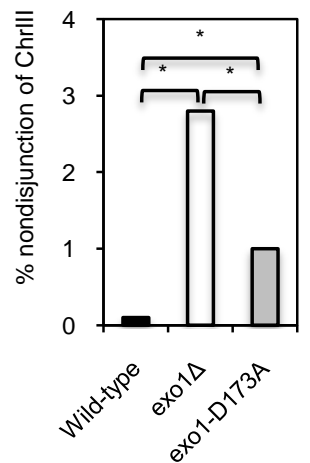




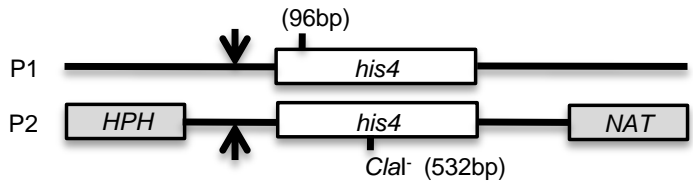

(B)

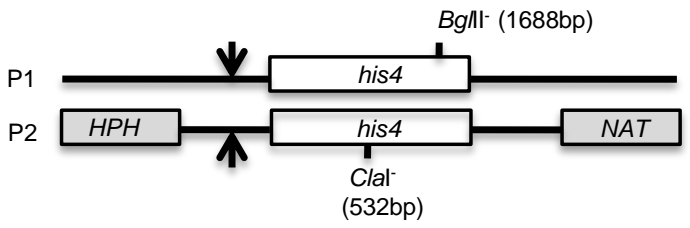


(A)
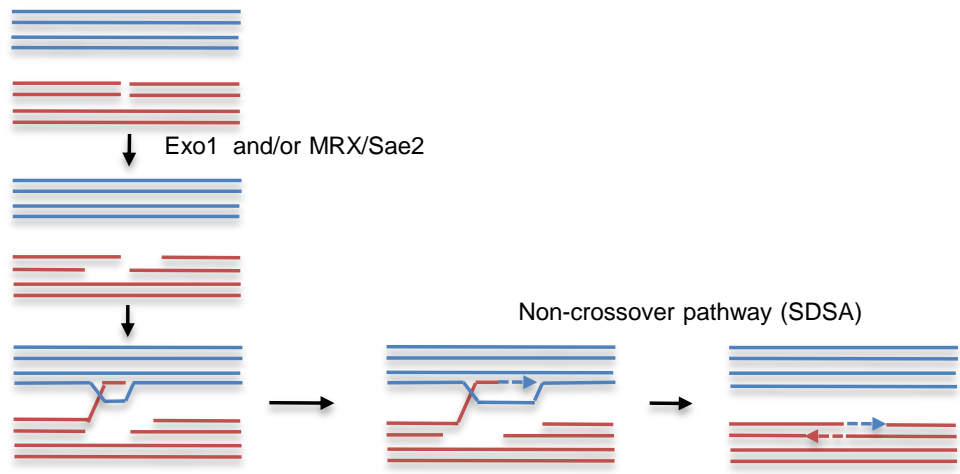

Noncrossover

$\downarrow$ Crossover pathway

(B)
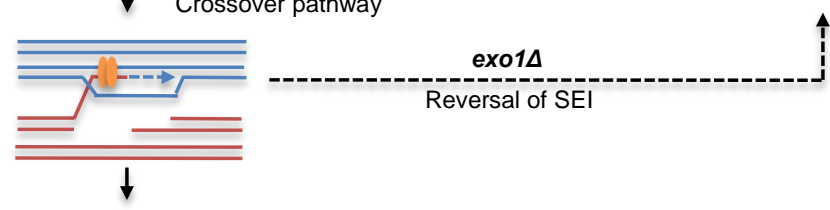

(C)

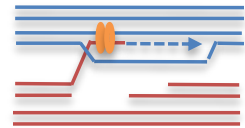

(D)
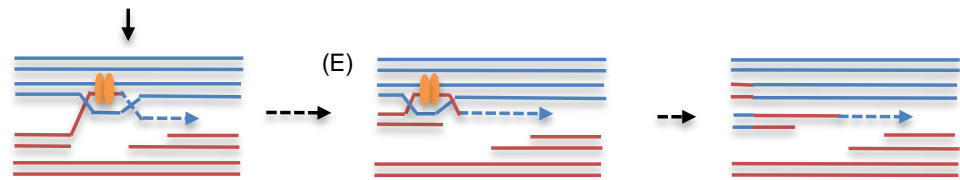

Halfcrossover and a broken chromatid

(F)
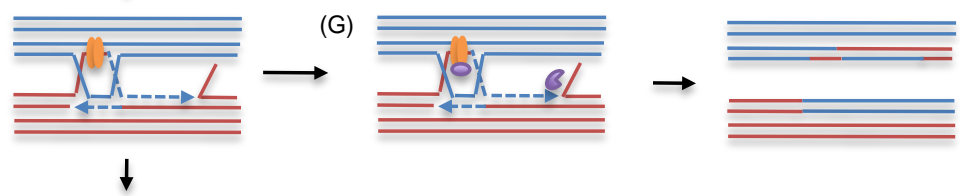

\section{EX01} Crossover

(H)
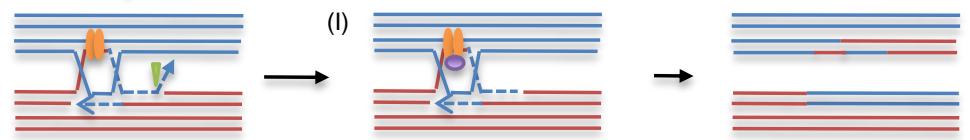

exo1-D173A

Crossover

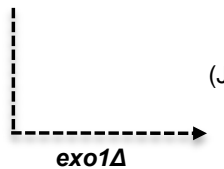

(J)
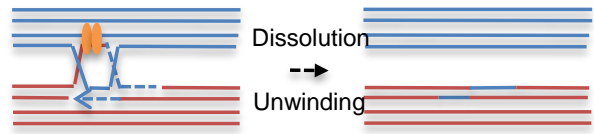

Noncrossover 
Supplemental Table 1 - Map Distances

\begin{tabular}{|c|c|c|c|}
\hline & Wild-type & exold & exo1-D173A \\
\hline \multicolumn{4}{|c|}{ HIS4-LEU2 } \\
\hline $\mathrm{PD}^{\mathrm{a}}$ & 449 & 540 & 206 \\
\hline NPD & 1 & 1 & 1 \\
\hline TT & 183 & 126 & 59 \\
\hline $\mathrm{cM}$ & $14.9^{\dagger}$ & $9.9^{*}$ & 12.2 \\
\hline \multicolumn{4}{|c|}{ LEU2-MAT } \\
\hline PD & 442 & 622 & 172 \\
\hline NPD & 32 & 7 & 3 \\
\hline $\mathrm{TT}$ & 425 & 244 & 140 \\
\hline $\mathrm{cM}$ & $34.3^{\dagger}$ & $16.4^{*}$ & $25.1^{* \dagger}$ \\
\hline \multicolumn{4}{|c|}{ CEN8-ARG4 } \\
\hline PD & 696 & 739 & 248 \\
\hline NPD & 2 & 1 & 1 \\
\hline $\mathrm{TT}$ & 185 & 119 & 52 \\
\hline $\mathrm{cM}$ & $11.2^{\dagger}$ & $7.3^{*}$ & 9.6 \\
\hline \multicolumn{4}{|c|}{ LYS5-MET13 } \\
\hline PD & 555 & 680 & 169 \\
\hline NPD & 8 & 2 & 5 \\
\hline $\mathrm{TT}$ & 349 & 186 & 131 \\
\hline $\mathrm{cM}$ & $21.8^{\mathrm{c}}$ & $11.4^{*}$ & $26.4^{\dagger}$ \\
\hline \multicolumn{4}{|c|}{ MET13-CYH2 } \\
\hline PD & 738 & 774 & 257 \\
\hline NPD & 0 & 0 & 2 \\
\hline TT & 179 & 99 & 51 \\
\hline $\mathrm{cM}$ & $9.8^{\dagger}$ & $5.7^{*}$ & $10.2^{\dagger}$ \\
\hline \multicolumn{4}{|c|}{ CYH2-TRP5 } \\
\hline PD & 331 & 539 & 114 \\
\hline NPD & 35 & 11 & 10 \\
\hline $\mathrm{TT}$ & 557 & 328 & 189 \\
\hline $\mathrm{cM}$ & $41.5^{\dagger}$ & $22.4^{*}$ & $39.8^{\dagger}$ \\
\hline \multicolumn{4}{|c|}{$\begin{array}{l}\text { a PD, NPD and TT represent parental ditypes, nonparental ditypes and tetratypes } \\
\text { respectively. cM values were calculated as described in Methods } 2.3 \text {. } \\
\text { Comparisons were made using the G-test of homogeneity and statistically } \\
\text { significant }(\mathrm{p}<0.0258) \text { differences are indicated as follows: }{ }^{*} \text { significantly different } \\
\text { from wild-type, }{ }^{\dagger} \text { significantly different from exol } \Delta .\end{array}$} \\
\hline
\end{tabular}


Supplemental Table 2 - Spore viability at $23^{\circ} \mathrm{C}$ and $33^{\circ} \mathrm{C}$

\begin{tabular}{|c|c|c|c|c|c|c|c|c|c|}
\hline \multirow[b]{2}{*}{ Genotype } & \multirow[b]{2}{*}{$\left({ }^{\circ} \mathrm{C}\right)$} & & Viable & spores & per tetr & ad class & \multicolumn{2}{|c|}{$\begin{array}{c}\text { Total } \\
\text { tetrads }\end{array}$} & \multirow[t]{2}{*}{$\begin{array}{c}\% \% \\
\text { viability }^{\mathrm{a}}\end{array}$} \\
\hline & & & 4 & 3 & 2 & 1 & $\mathbf{0}$ & & \\
\hline Wild-type & 23 & $\begin{array}{c}n \\
(\%)\end{array}$ & $\begin{array}{c}941 \\
(89.9)\end{array}$ & $\begin{array}{c}54 \\
(5.2)\end{array}$ & $\begin{array}{c}41 \\
(3.9)\end{array}$ & $\begin{array}{c}2 \\
(0.2)\end{array}$ & $\begin{array}{c}8 \\
(0.8)\end{array}$ & 1046 & $95.8^{\dagger}$ \\
\hline Wild-type & 33 & $\begin{array}{c}n \\
(\%)\end{array}$ & $\begin{array}{c}309 \\
(92.2)\end{array}$ & $\begin{array}{c}21 \\
(6.3)\end{array}$ & $\begin{array}{c}2 \\
(0.6)\end{array}$ & $\begin{array}{c}0 \\
(0)\end{array}$ & $\begin{array}{c}2 \\
(0.6)\end{array}$ & 334 & $97.5^{* \dagger}$ \\
\hline exols & 23 & $\begin{array}{c}n \\
(\%)\end{array}$ & $\begin{array}{c}885 \\
(40.2)\end{array}$ & $\begin{array}{c}231 \\
(10.5)\end{array}$ & $\begin{array}{c}472 \\
(21.5)\end{array}$ & $\begin{array}{c}136 \\
(6.2)\end{array}$ & $\begin{array}{c}476 \\
(21.6)\end{array}$ & 2200 & $60.4^{*}$ \\
\hline exols & 33 & $\begin{array}{c}n \\
(\%)\end{array}$ & $\begin{array}{c}220 \\
(66.3)\end{array}$ & $\begin{array}{c}33 \\
(9.9)\end{array}$ & $\begin{array}{c}45 \\
(13.6)\end{array}$ & $\begin{array}{c}10 \\
(3.0)\end{array}$ & $\begin{array}{c}23 \\
(6.9)\end{array}$ & 331 & $81.5^{* \dagger}$ \\
\hline $\begin{array}{l}\text { exol- } \\
D 173 A\end{array}$ & 23 & $\begin{array}{c}n \\
(\%)\end{array}$ & $\begin{array}{c}319 \\
(38.3)\end{array}$ & $\begin{array}{c}198 \\
(23.8)\end{array}$ & $\begin{array}{c}199 \\
(23.9)\end{array}$ & $\begin{array}{c}66 \\
(7.9)\end{array}$ & $\begin{array}{c}49 \\
(5.9)\end{array}$ & 831 & $70.2^{* \dagger}$ \\
\hline
\end{tabular}

${ }^{\text {a }}$ Overall viabilities were calculated as $(4 \mathrm{x}$ no. of four spore tetrads $+3 \mathrm{x}$ no. of three-spore tetrads $+2 \mathrm{x}$ no. of two-spore tetrads + no. of one-spore tetrads $) /(4 \mathrm{x}$ total no. of tetrads) x 100. Comparisons were made using the G-test of homogeneity and statistically significant $(p<0.0127)$ differences are indicated as follows: ${ }^{*}$ significantly different from wild-type at $23^{\circ} \mathrm{C},{ }^{\dagger}$ significantly different from exol $\Delta$ at $23^{\circ} \mathrm{C}$. 
Supplemental Table 3 - Rates of chromosome III non-disjunction at meiosis I

\begin{tabular}{cccc}
\hline Genotype & $\begin{array}{c}\text { Number of non- } \\
\text { maters }\end{array}$ & Total tetrads & $\begin{array}{c}\text { \% Non- } \\
\text { disjunction }^{\text {a }}\end{array}$ \\
\hline Wild-type & 1 & 1046 & $0.1^{\dagger}$ \\
exo1 1 & 61 & 2200 & $2.8^{*}$ \\
exo1-D173A & 8 & 832 & $1.0^{* \dagger}$ \\
\hline
\end{tabular}

${ }^{a}$ Non-disjunction was calculated as: (number of non-maters/total number of tetrads) $\mathrm{x} 100$. Comparisons were made using the G-test of homogeneity and statistically significant $(\mathrm{p}<0.0258)$ differences are indicated as follows: ${ }^{*}$ significantly different from wild-type, ${ }^{\dagger}$ significantly different from exol $\Delta$. 
(A)

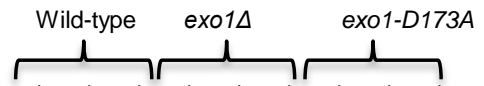

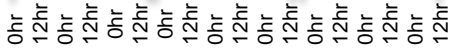
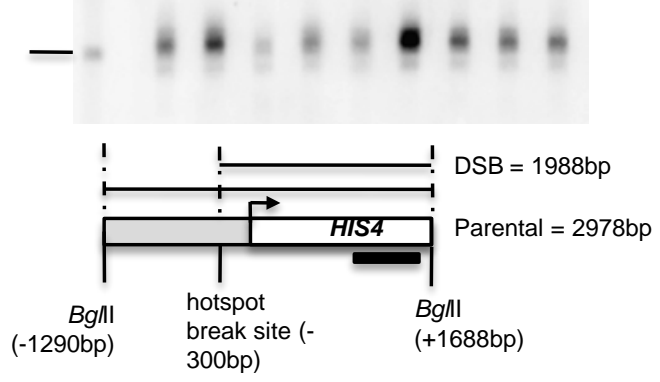

(B)

총

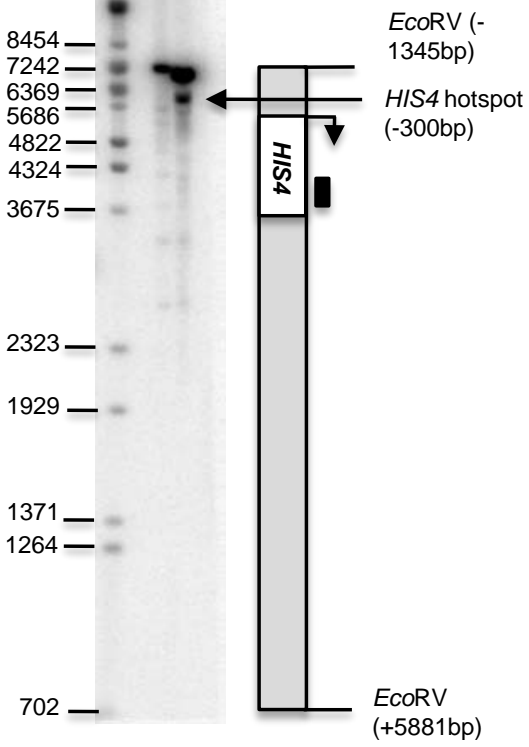



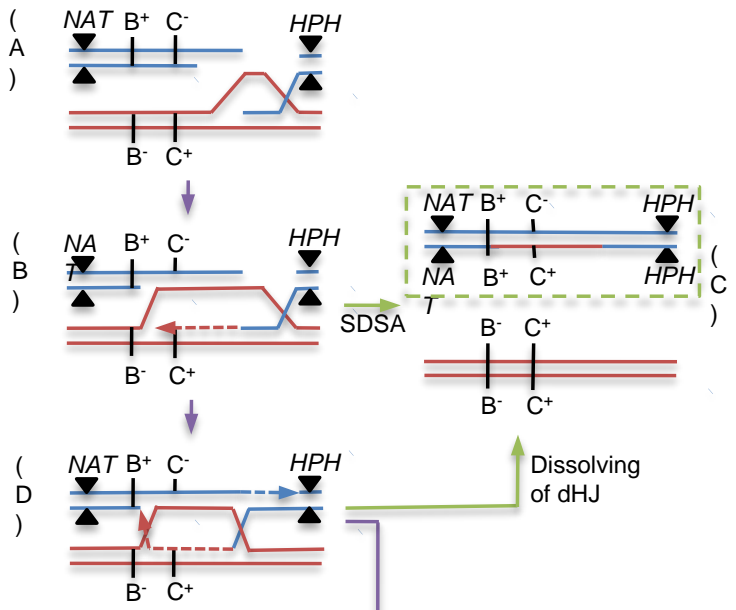

Dissolving of $\mathrm{dHJ}$
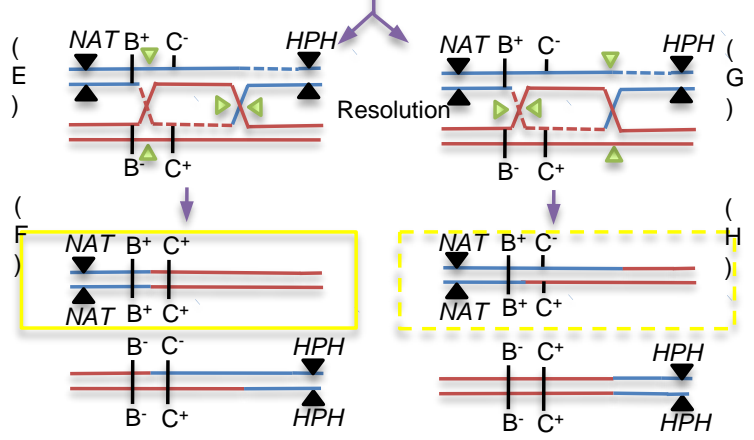


\section{Supplemental Figure 1 - DSB formation at HIS4 in rad50S strains}

(A) DSBs at HIS4 were assessed in rad50S strains in three independent wild-type, exo1 $\Delta$ and exo1-D173A cultures. DNA was digested with $B g l \mathrm{II}$ in order to estimate the total amount of breaks formed and the position of the break with respect to the HIS4 start codon. The mean amount of DSBs produced in wild-type cells (RKD80) was $12.8 \%, 14.7 \%$ in an exo1 $\Delta$ strain (RKD81) and $13.2 \%$ in exo1-D173A (RKD82). These values were not significantly different from one another ( $\mathrm{p}>0.7, t$-test). (B) DNA from a rad50S culture was digested with EcoRV to look for the presence of DSBs downstream of HIS4. BstEII digested lambda DNA was used as a molecular weight standard and the size of each band is indicated. The black boxes represent the approximate location of the probe used for DSB analysis.

\section{Supplemental Figure 2 - An example illustrating prototroph formation between heteroalleles}

In this example, a his4-cla/his4-bgl heteroallelic cross is presented. Cassettes conferring resistance to nourseothricin and hygromycin $\mathrm{B}$ are inserted on the his4-cla chromosome. (A) In such crosses, prototrophs most commonly arise when DSBs occur on the chromosome containing the mutant allele situated closest to the break site (in this case, his4-cla). (B) Following strand invasion, DNA synthesis then takes place using the his4-bgl strand as a template. If this synthesis terminates between the his4-cla and his4-bgl sites, a HIS4 strand is produced. (C) If the invading strand is then displaced to form a non-crossover, a $\mathrm{His}^{+}$spore may result depending upon the direction of mismatch repair. This spore will be both $\mathrm{Nat}^{\mathrm{R}}$ and $\mathrm{Hyg}^{\mathrm{R}}$ (D) Alternatively, if the break is to be repaired as a crossover, a dHJ intermediate will be produced. (E) Resolution of this $\mathrm{dHJ}$ in one orientation (indicated by green triangles) will yield a His ${ }^{+}$spore (F). (G) Resolution in the alternative orientation may also produce a His ${ }^{+}$spore $(\mathrm{H})$, depending upon the directionality of mismatch repair. In both cases, the $\mathrm{His}^{+}$spore will by $\mathrm{Nat}^{\mathrm{R}} \mathrm{Hyg}^{\mathrm{S}}$. Boxes indicate potential sources of $\mathrm{His}^{+}$ spores. 